\title{
Método para planejamento e controle da produção baseado em zonas de trabalho com o apoio de BIM
}

\author{
Method for location-based production planning and \\ control supported by BIM
}

\section{Fabrício Berger de Vargas \\ Carlos Torres Formoso}

\section{Resumo}

A

abordagem de planejamento e controle da produção (PCP) baseada em zonas de trabalho tem como vantagem explicitar o fluxo de trabalho ao longo das unidades de produção, podendo ser associado ao Sistema Last Planner (LPS) e a modelos BIM 4D. Entretanto, ainda existem algumas lacunas de conhecimento, tanto práticas como teóricas, referentes à implementação desta abordagem, principalmente relativas à aplicação de conceitos e princípios da filosofia da produção enxuta e a interação destes com as funcionalidades BIM. Destaca-se a necessidade de desenvolver estudos sobre métodos de PCP que considerem a natureza parcialmente repetitiva das atividades de construção e aspectos relacionados à gestão dos fluxos de trabalho e do produto. O presente trabalho propõe um método para PCP baseado em zonas de trabalho com o apoio de BIM, e explora a sua interface com o LPS. A abordagem metodológica utilizada foi a Design Science Research, sendo conduzidos dois estudos empíricos em empresas atuantes no mercado imobiliário. As principais contribuições do método proposto estão ligadas às ferramentas utilizadas, que podem potencialmente contribuir para aumentar a qualidade da informação, principalmente relacionadas a fluxos de trabalho, e dar suporte para a tomada de decisão colaborativa.

Palavras-chave: Planejamento baseado na localização. Planejamento e Controle da Produção. Modelagem da Informação na Construção. Sistema Last Planner (LPS). Simulação 4D.

\begin{abstract}
The location-based approach for production planning and control has the advantage of making explicit the workflow throughout the production units, allowing to make a connection to the Last Planner System (LPS) and 4D BIM models. However, there are still some knowledge gaps, in both practice and research, regarding the implementation of this approach. Those gaps are mainly related to the application concepts and principles of the lean production philosophy, and their interaction with BIM functionalities. Indeed, it is necessary to develop studies not only on planning and control methods that consider the

partially repetitive nature of construction activities, but also on the aspects related to work and product flow management. The aim of this study is to propose a Location-Based Planning and Control method supported by BIM and explore its interface with LPS. Design Science Research was the methodological approach adopted in this investigation and two empirical studies were carried out in real estate companies. The main contributions of the proposed method are related to the tools adopted, which can potentially contribute to improve the quality of information, mainly related to workflows, and to provide support to collaborative decision-making.
\end{abstract}

'Fabricio Berger de Vargas ${ }^{1}$ Universidade Federal do Rio Grande Porto Alegre - RS - Brasil

${ }^{2}$ Carlos Torres Formoso 2 Universidade Federal do Rio Grande do Sul Porto Alegre - RS - Brasil

Recebido em 24/03/19 Aceito em 27/08/19
Keywords: Location-based planning. Production Planning and Control. Building Information Modeling. Last Planner System (LPS). 4D simulation. 


\section{Introdução}

O planejamento é um processo de tomada de decisão que facilita a compreensão dos objetivos do empreendimento e produz informações que servem como referência básica para monitorar e controlar a execução de empreendimentos de construção (LAUFER, 1990), sendo efetivo somente se for seguido de um controle (FORMOSO, 1991).

Os métodos tradicionais de planejamento e controle da produção (PCP) utilizados na indústria da construção possuem limitações (KOSKELA; HOWELL, 2002), sendo fortemente criticados na literatura por não considerarem devidamente as interferências entre processos, a variabilidade de processos, incertezas na disponibilidade de recursos, e por resultarem em excesso de folgas de tempo, o que tende a aumentar a duração dos empreendimentos (LAUFER; TUCKER, 1987; REDA, 1990; RUSSEL; WONG, 1993; KOSKELA et al., 2014).

Particularmente, o Método do Caminho Crítico (CPM), amplamente disseminado na comunidade de gestão de empreendimentos, tem recebido muitas críticas por possuir limitações relacionadas ao balanceamento de equipes (RUSSELL; WONG, 1993; HAMZEH; ZANKOUL; ROUHANA, 2015) e a continuidade do uso de recursos (MATTILA; PARK, 2003; BENJAORAN; TABYANG; SOOKSIL, 2015). Koskela et al. (2014) afirmam que o método CPM tende a ser mais utilizado como uma forma de gerenciar contratos do que utilizado para a gestão da produção.

Além disso, os métodos tradicionais de PCP têm sido criticados por não darem suporte à natureza repetitiva dos empreendimentos de construção (HARRIS; IOANNOU, 1998; HEGAZY, KAMARAH, 2008), apresentando dificuldades em termos de permitir a visualização dos fluxos de trabalho em múltiplos locais e os processos repetitivos. Por outro lado, técnicas utilizadas para explorar a natureza repetitiva da atividade de construção, geralmente partem da premissa de que um empreendimento pode ser dividido em diversas unidades idênticas (HUANG; SUN, 2005). Entretanto, um empreendimento de construção é normalmente composto por diferentes espaços com diferentes graus de similaridades entre eles (SACKS, 2016), sendo que a característica repetitiva do processo de construção depende também da aplicação de alguns princípios de gestão da produção, tais como reduzir o tamanho do lote e reduzir o trabalho em progresso (VALENTE et al., 2014).

Nesse contexto, merecem destaque dois modelos de PCP que se contrapõem às práticas tradicionais do setor da construção pela introdução de mudanças conceituais: o Sistema Last Planner e o PCP baseado em zonas de trabalho (Location-Based Planning ou Management System).

O Sistema Last Planner (LPS) é fortemente baseado em conceitos e princípios da filosofia da produção enxuta (lean production), tendo sido aplicado com sucesso em diversos empreendimentos de construção (BALLARD, 2000). Segundo Tommelein e Ballard (1997), o LPS utiliza o mecanismo de puxar a produção, buscando de forma proativa evitar a falta de recursos para que as novas atividades iniciem. Este mecanismo de puxar a produção libera o trabalho com base no status do sistema, permitindo assim limitar a quantidade de trabalho em progresso existente (HOPP; SPEARMAN, 2000). O LPS foca na redução da variabilidade e da incerteza presentes nos fluxos de trabalho da construção e busca proteger a produção dos seus efeitos nocivos (HAMZEH; BALLARD; TOMMELEIN, 2012).

A abordagem de PCP baseada em zonas de trabalho consiste em uma tentativa de ampliar o uso da técnica da linha de balanço, por meio da agregação de um conjunto de conceitos e princípios da produção enxuta, tanto no planejamento como no controle da produção. Esta abordagem permite visualizar os fluxos de trabalho, simular e discutir diferentes alternativas para o sequenciamento das atividades, ao mesmo tempo que traz informações de quando e onde cada atividade deve ser realizada (KENLEY; SEPPÄNEN, 2010).

Dave et al. (2015) sugerem que seja explorada a complementaridade entre o LPS e o PCP baseado em zonas de trabalho, visto que existem limitações no papel desempenhado por cada uma destas abordagens. Seppänen, Ballard e Pesonen (2010) analisaram como os elementos de cada uma destas abordagens podem ser combinados a fim de melhorar o desempenho do empreendimento. Entretanto, a combinação destes dois modelos não foi suficientemente explorada em casos reais, não tendo sido realizada uma discussão mais profunda a respeito da problemática envolvida nesta integração. Olivieri, Granja e Picchi (2016) propuseram um modelo integrado que incorpora à abordagem tradicional, Critical Path Method (CPM), aspectos do LBM e do LPS. Este modelo enfatiza a abordagem tradicional CPM e não considera a utilização de modelos BIM para apoio ao PCP. Este modelo precisa ainda ser aplicado em situações reais práticas em conjunto com conceitos mais avançados da filosofia da produção enxuta para avaliar a sua utilidade e aplicabilidade. Já Biotto, Formoso e Isatto (2015) propuseram um método que contribui com o uso da modelagem BIM 4D no 
apoio à tomada de decisão na gestão do sistema de produção de empreendimentos de construção, mas que não explora a fundo aspectos do LPS e nem considera a abordagem baseada em zonas de trabalho.

No presente trabalho, a utilização de modelos BIM 4D juntamente com ferramentas como a linha de balanço surge com um potencial a ser investigado, a fim de entender como, em conjunto, permitem estudar os fluxos de trabalho, verificar falhas no sequenciamento das atividades, avaliar a viabilidade de planos propostos e identificar alternativas de planos para a execução. Esta conexão foi explorada nos trabalhos de Björnfot e Jongeling (2007), os quais utilizaram a linha de balanço em conjunto com um modelo 4D em um estudo de caso, e no trabalho de Jongeling e Olofsson (2007), que sugeriram que a abordagem de PCP baseada em zonas de trabalho tenha o apoio de BIM 4D, de forma a associar a visualização de fluxos de trabalho a modelos BIM. Entretanto, nenhum dos referidos trabalhos consideraram a integração com o LPS e as discussões sobre as informações a serem extraídas dos modelos para apoio da tomada de decisão são limitadas.

BIM 4D pode facilitar a implementação de processos colaborativos na gestão da produção (CROTTY, 2012), fornecer informações importantes sobre os recursos necessários para executar as tarefas (EASTMAN et al., 2011), e visualizar espacialmente o progresso da obra e as interferências entre atividades ocorrendo em um mesmo local (SACKS, 2016). Nesse sentido, melhorias advindas da adoção de BIM podem permitir aos gestores produzir planos mais confiáveis, além de comunicar decisões de planejamento de forma mais efetiva, permitindo assim melhor gerenciar as equipes de produção (EASTMAN et al., 2011).

Portanto, o objetivo do presente trabalho consiste em propor um método para PCP baseado em zonas de trabalho, com o apoio de BIM. São propostos os diferentes passos necessários para a aplicação deste método, visando integrar o PCP baseado em zonas de trabalho ao LPS, nos quais é destacada a aplicação de conceitos e princípios da filosofia da produção enxuta.

\section{Referencial teórico}

\section{Sistema Last Planner}

O LPS pode ser entendido como um modelo de PCP que possui um mecanismo de transformação do que deveria ser feito no que poderia ser realizado, formando pacotes de trabalho semanais (BALLARD, 2000). Esta abordagem difere do processo tradicional, que parte para a execução do plano a partir da definição do que deveria ser feito, assumindo assim, que todos os recursos necessários às atividades estão disponíveis quando a atividade iniciar (TOMMELEIN; BALLARD, 1997). No LPS, o PCP é normalmente dividido em três níveis hierárquicos: planejamento de longo, médio e curto prazo (HAMZEH; BALLARD; TOMMELEIN, 2012).

No planejamento de longo prazo, realizado nas fases iniciais do empreendimento, há um baixo grau de detalhamento, devido às incertezas presentes no ambiente produtivo (BALLARD; HOWELL, 1997). Logo, nesse nível identifica-se as datas marco, geralmente ligadas à gestão de contratos (TOMMELEIN; BALLARD, 1997), e as metas principais do empreendimento (LAUFER, 1997).

No planejamento de médio prazo (look-ahead), o horizonte de planejamento é móvel e a elaboração do plano é feita a partir do processo de triagem das atividades que devem ser incluídas no plano de curto prazo (TOMMELEIN; BALLARD, 1997). O plano de médio prazo é essencial para melhorar a eficácia do PCP, visto que neste nível deve-se identificar e eliminar as restrições, para que as atividades planejadas no nível de curto prazo possam ser efetivamente executadas (BALLARD, 2000).

No planejamento de curto prazo, são definidos pacotes de trabalho semanais, a partir da análise de quais atividades possuem os recursos disponíveis e realmente podem ser executadas. $\mathrm{O}$ foco dado ao comprometimento das equipes com a execução dos pacotes definidos é uma forma de buscar um fluxo de trabalho estável (BALLARD; HOWELL, 1998). O aumento da colaboração entre as equipes permite que as partes interessadas saibam das interdependências entre as atividades (VIANA, 2015).

\section{Planejamento e controle da produção baseado em zonas de trabalho}

O PCP baseado em Zonas de Trabalho é uma abordagem utilizada para planejar e controlar os processos da construção considerando a relação entre tempo e local (KENLEY; SEPPÄNEN, 2010). Zona de trabalho refere-se a um volume, espacialmente delimitado e bem definido, resultado da quebra do projeto em locais menores, que é a base para planejar, analisar e controlar o trabalho na medida em que este flui por diferentes zonas (KENLEY; SEPPÄNEN, 2010). 
Segundo Kenley e Seppänen (2010), é possível que um empreendimento seja desmembrado espacialmente de diferentes maneiras. Esse desmembramento dá origem à Estrutura Hierárquica de Zonas de Trabalho (EHZT), sendo que uma zona de trabalho em um nível superior abrange um conjunto de zonas de trabalho menores, originárias da quebra desta em níveis inferiores. Cada nível possui um propósito diferente, sendo que as zonas de níveis superiores permitem analisar o sequenciamento de partes independentes do empreendimento. As de níveis intermediários são usadas para planejar o fluxo de execução dos elementos construtivos e normalmente refletem as restrições físicas. Já as zonas de níveis mais baixos devem ser aplicáveis à maioria das especialidades em execução em uma determinada fase, sendo pequenas o suficiente de forma que apenas uma especialidade possa estar alocada na zona. Nesse nível deve ser possível de planejar e controlar os detalhes e acabamentos (KENLEY; SEPPÄNEN, 2010). Na situação de apenas uma EHZT não atender à execução de todas as tarefas, pode-se definir diferentes sistemas de localização. Nesse caso, divide-se o mesmo espaço físico em mais de uma configuração, criando assim estruturas hierárquicas distintas abaixo do nível em que foram definidos os sistemas de localização (VICO..., 2016).

Esta abordagem facilita a utilização de ferramentas visuais para apresentar os planos, como, por exemplo, a linha de balanço, sendo que se busca executar uma atividade por vez em cada zona de trabalho (BØLVIKEN; ASLESEN; KOSKELA, 2015). Assim, o foco é dado ao deslocamento dos recursos de um local para outro sem esperar, planejando-se assim um fluxo ininterrupto (SEPPÄNEN, 2014). A linha de balanço representa o fluxo da produção ao longo das zonas de trabalho, e a sua representação em forma de linha permite identificar o ritmo de produção da tarefa por meio da sua inclinação (BIOTTO et al., 2017). Segundo Lucko, Alves e Angelim (2014), esta abordagem permite que se identifique, visualize e utilize de forma explícita conceitos importantes ao PCP, os quais são apresentados na Figura 1. Um dos princípios fundamentais da filosofia da Produção Enxuta é criar fluxo contínuo do produto nos processos de produção (WOMACK; JONES, 1996). Em uma situação de balanceamento das atividades, tem-se ainda uma melhor situação, em que tanto o fluxo do produto é contínuo, como o fluxo de trabalho das equipes não sofre interrupções. Balancear, neste contexto, refere-se à criação de um ritmo de trabalho sincronizado e estável, de acordo com a demanda para cada serviço ao longo das zonas de trabalho (FRANDSON; SEPPÄNEN ; TOMMELEIN, 2015).

Lucko, Alves e Angelim (2014) afirmam que estes conceitos permitem definir como as diferentes especialidades interagem no sistema de produção, permitindo gerir de forma explícita os fluxos de trabalho na obra, ao mesmo tempo que suporta a tomada de decisão em diferentes níveis de planejamento. No nível de planejamento de longo prazo, esta abordagem permite obter uma visão geral das informações a respeito dos locais, fluxo de trabalho, simultaneidade e interferências (LUCKO; ALVES; ANGELIM, 2014). No nível de médio prazo, pode-se visualizar a localização real das diferentes especialidades e formas de rearranjá-las, enquanto, no nível de curto prazo, facilita o monitoramento dos pacotes de trabalho semanais, alocados em diferentes zonas de trabalho (LUCKO; ALVES; ANGELIM, 2014).

\section{Figura 1 - Conceitos importantes ao PCP}

\section{Conceitos}

Atividade concluída - atividade que foi executada com qualidade

Buffers - folgas de tempo ou espaço utilizadas para proteger o sistema de produção da incerteza e da variabilidade (HORMAN et al., 2003)

Conflito espacial - diferentes atividades acontecendo na mesma zona de trabalho

Lead time de produção - tempo total para executar uma zona de trabalho (HOPP; SPEARMAN. 2000)

Ritmo de produção - divisão da quantidade de unidades pelo tempo de produção (Yassine et al., 2014)

Sequenciamento das atividades - ordenamento das atividades a serem executadas Simultaneidade - atividades acontecendo ao mesmo tempo em diferentes zonas de trabalho Sincronia das tarefas - tarefas com ritmos de produção balanceados

Lotes de transferência - tamanho dos lotes acumulados que vão ser transferidos para posteriores operações (HOPP; SPEARMAN, 2000)

Lote de produção - tamanho dos lotes que serão processados antes que outros lotes sejam novamente processados (HOPP; SPEARMAN, 2000)

Tempo de ciclo - tempo de movimentação, preparação e processamento para completar uma atividade em uma zona de trabalho (HOPP; SPEARMAN, 2000)

Trabalho em progresso - estoque presente entre os pontos inicial e final da produção, desconsiderando os estoques de produtos acabados (HOPP; SPEARMAN, 2000) 


\section{Uso de modelos BIM 4D para planejamento e controle da produção}

A definição de zonas de trabalho para o planejamento da produção tem sido explorada em estudos sobre o projeto do sistema de produção (PSP), que pode ser definido como um processo de formulação e análise de diferentes alternativas de estruturação e organização dos processos que constituem o sistema de produção do empreendimento (SCHRAMM; FORMOSO, 2015). Alguns destes estudos combinaram a utilização de modelos 4D com o uso da linha de balanço, tais como Schramm (2009), Biotto (2012) e Reck (2013).

Schramm (2009) propôs um método para elaboração de PSP com o uso de simulação de eventos discretos e posteriormente reportou os resultados na forma de uma sequência de imagens 3D da obra, mas sem utilizar BIM. Reck (2013) expandiu um pouco mais o método proposto por Schramm (2009) por meio de uma maior gama de ferramentas visuais do sistema de produção. O foco destes dois estudos foi na geração de diferentes cenários de projeto de sistema de produção e na definição do plano de longo prazo, sendo dada pouca ênfase ao planejamento e controle da produção nos níveis de médio e curto prazo. Biotto (2012), por sua vez, explorou o uso de BIM 4D em diferentes níveis hierárquicos do PCP reproduzindo as decisões relacionadas ao modelo 4D em cada um dos horizontes de planejamento, mas não tratou das decisões de planejamento específicas a serem tomadas em cada um destes horizontes. O presente trabalho tem como foco principal o PCP, voltandose principalmente à simulação de diferentes cenários e a avaliação de alternativas ao longo dos ciclos de planejamento de médio e curto prazo.

Para entender como as funcionalidades BIM podem apoiar o PCP e contribuir para a implementação de conceitos e princípios da produção enxuta no contexto de PCP baseado em zonas de trabalho, foram selecionadas algumas interações entre as funcionalidades BIM e os princípios Lean a partir da matriz proposta por Sacks et al. (2010). Considerando as 56 interações apontadas pelos referidos autores, sete foram identificadas como relevantes ao presente trabalho, as quais estão apresentadas e justificadas na Figura 2.

\section{Método de pesquisa}

\section{Abordagem metodológica}

Esta pesquisa adotou como abordagem metodológica a Design Science Research (DSR), em que se busca desenvolver conceitos de solução para resolver classes de problemas, ao mesmo tempo que se desenvolve um referencial teórico para explicar o problema identificado e prescrever a solução desenvolvida (HOLMSTRÖM; KETOKIVI; HAMERI, 2009).

Nesta pesquisa, a DSR é considerada como uma abordagem metodológica ampla, de caráter prescritivo, na qual podem ser utilizadas diferentes estratégias de pesquisa. A estratégia de pesquisa adotada foi similar à pesquisa ação (Action Research - AR), cuja origem é nas ciências sociais. Este posicionamento, já adotado no trabalho de Viana (2015), é discutido por Järvinen (2007), que aponta diversas similaridades e complementaridades entre DSR e AR. A forte interação e a presença de cooperação entre as empresas envolvidas e o pesquisador, bem como os ciclos de aprendizado e reflexões incorporados na fase de implementação, típicos da AR, contribuíram para a proposição do artefato deste estudo. Assim, a estratégia de pesquisa adotada no presente trabalho envolveu intervenções do pesquisador para resolver os problemas estudados, ou seja, de forma similar a uma pesquisa ação (EDEN; HUXHAM, 1996), os efeitos das mudanças nos sistemas sociais foram observadas ao longo da pesquisa.

O artefato principal deste trabalho é o método de PCP que combina PCP baseado em zonas de trabalho, LPS e BIM 4D, a fim de solucionar problemas relacionados a gestão dos fluxos de produção de empreendimentos de construção. O método proposto emergiu a partir das necessidades identificadas nos estudos empíricos.

\section{Delineamento da pesquisa}

A pesquisa é composta por dois estudos empíricos, conforme apresentado na Figura 3, realizados nas empresas A e B. O desenvolvimento de dois estudos teve como propósito permitir a realização de dois grandes ciclos de aprendizagem na implementação, nos quais a solução foi refinada, e facilitar a abstração dos resultados da pesquisa. Cada um dos estudos possuiu ciclos de aprendizagem mais curtos, típicos de uma pesquisa ação, sendo os mesmos divididos em: fase de compreensão, fase de desenvolvimento e teste, e fase de análise e reflexão. 
Figura 2 - Interações entre as funcionalidades BIM e os princípios Lean

\begin{tabular}{|c|c|}
\hline FUNCIONALIDADE BIM & PRINCÍPIO LEAN \\
\hline - Visualização do projeto & $\begin{array}{l}\text { - Simplificar por meio do projeto de sistemas } \\
\text { produtivos orientados ao fluxo e valor }\end{array}$ \\
\hline \multicolumn{2}{|c|}{$\begin{array}{l}\text { Modelos BIM simplificam o entendimento dos projetos, permitindo que a informação fique acessível aos participantes } \\
\text { não técnicos do projeto, e ainda auxilia os planejadores a lidar com empreendimentos complexos. Os modelos BIM } \\
\text { orientados ao fluxo e valor, permitem projetar o sistema de produção de forma a garantir a capacidade do sistema e o } \\
\text { fluxo, dando suporte ao controle da produção e a melhoria contínua. }\end{array}$} \\
\hline- Fonte de informação única & - Reduzir a variabilidade do produto \\
\hline \multicolumn{2}{|c|}{$\begin{array}{l}\text { Com a utilização de BIM, a informação possui fonte única, e as múltiplas representações são geradas e alteradas de } \\
\text { forma automática, reduzindo a variabilidade do produto e mantendo a consistência das informações. }\end{array}$} \\
\hline $\begin{array}{c}\text { - Geração automática das tarefas } \\
\text { - Simulação dos processos da construção } \\
\text { - Visualização 4D do planejamento da construção }\end{array}$ & - Reduzir a duração dos ciclos de produção \\
\hline \multicolumn{2}{|c|}{$\begin{array}{l}\text { As três funcionalidades BIM listadas permitem reduzir o tempo de ciclo das tarefas, visto que permitem identificar } \\
\text { antecipadamente conflitos existentes no plano, e resultam em cronogramas melhores e com menos conflitos. }\end{array}$} \\
\hline $\begin{array}{c}\text { - Visualização do status do processo } \\
\text { - Comunicação online da informação do produto e processo }\end{array}$ & $\begin{array}{c}\text { - Uso de sistemas puxados } \\
\text { - Visualizar os processos de produção por meio da } \\
\text { gestão visual }\end{array}$ \\
\hline \multicolumn{2}{|c|}{$\begin{array}{l}\text { A visualização e a comunicação do status do processo são elementos-chave para permitir que as equipes de produção } \\
\text { priorizem finalizar as zonas de trabalho em execução para seguir para as subsequentes, de forma a contribuir e garantir } \\
\text { um fluxo ininterrupto de trabalho, e assim implementar um fluxo puxado. Em um sistema puxado, as atividades são } \\
\text { desencadeadas pela demanda de uma estação de trabalho à jusante, ou pelo cliente. }\end{array}$} \\
\hline - Visualização 4D de cronogramas da construção & $\begin{array}{c}\text { - Redução da variabilidade da produção } \\
\text { - Visualizar os métodos de produção por meio da } \\
\text { gestão visual } \\
\text { - Visualizar os processos de produção por meio da } \\
\text { gestão visual }\end{array}$ \\
\hline
\end{tabular}

A utilização de ferramentas 4D permite acompanhar as fases de desenvolvimento do projeto e execução da construção, permitindo simular a produção, equipamentos e processos. Além disso, pode-se identificar conflitos de tempo, espaço e problemas de construtibilidade. Consequentemente, estas simulações permitem melhorar os processos, aumentar a eficiência, a segurança, e também ajudam a identificar gargalos e a melhorar os fluxos da construção.

- Simulação dos processos da construção

- Visualização 4D de cronogramas da construção - Visualização do status do processo
- Processo de geração de valor a partir da validação e verificação das informações

A visualização de cronogramas propostos e a visualização de processos em andamento permitem verificar e validar a informação do processo contra as especificações e exigências do cliente, a fim de gerar valor.

- Colaboração no projeto e na construção - Visualização por múltiplos usuários

- Visualização 4D de cronogramas da construção
- Resolução de problemas

- Decisões por consenso, considerar todas as opções

A visualização $4 \mathrm{D}$ do planejamento, a colaboração no projeto e na construção, e a comunicação da informação do produto e processos, podem apoiar e facilitar a tomada de decisões participativa, fornecendo mais e melhores informações à todos os envolvidos, e expande o leque de opções que podem ser consideradas. Além disso, ferramentas 4D permitem gerar e avaliar alternativas de planejamento de forma rápida.

Fonte: Sacks et al. (2010).

No estudo A foi inicialmente realizado um estudo exploratório, com o objetivo de entender o problema real e definir o escopo da pesquisa. Neste estudo exploratório foi analisado também o potencial de utilização do software Vico Office na presente pesquisa e realizado o treinamento de um dos autores no uso do mesmo. Este software foi escolhido por ser o único disponível para planejar empreendimentos com base em zonas de trabalho e que utiliza BIM 4D.

Em relação ao estudo na Empresa A, foi realizado na etapa de compreensão um diagnóstico da empresa e do Empreendimento E1, com o intuito de entender o contexto, analisar o sistema de PCP utilizado e identificar os problemas críticos que poderiam representar oportunidades de melhoria. Em seguida, foi desenvolvido o modelo BIM 3D do Empreendimento E1, que foi refinado na medida em que se avançou o estudo e novas necessidades surgiram. Na fase de desenvolvimento e teste, foi utilizado a linha de balanço e BIM 4D, ao longo dos ciclos de planejamento, coleta, análise e reflexão. Ao final deste estudo, foi concebido preliminarmente o método e houve uma discussão com representantes da empresa parceira sobre os resultados alcançados. 
No estudo empírico 2, buscou-se aplicar e refinar a versão preliminar do método. Na fase de compreensão buscou-se compreender o contexto em que a Empresa B e o Empreendimento E2 estavam inseridos. De forma paralela, foi analisado e adaptado o modelo BIM do Empreendimento B, que havia sido desenvolvido anteriormente, para utilizá-lo neste estudo. Na fase de desenvolvimento e teste houve diversos ciclos de PCP, com base no método proposto, que foi refinado à medida em que os dados eram coletados, analisados e discutidos. Este refinamento deu origem a segunda versão do método, apresentada no item 4.3. Ao final deste estudo, houve uma discussão dos resultados com representantes da empresa, assim como foram analisadas e avaliadas as contribuições práticas e teóricas da pesquisa.

\section{Descrição das empresas e dos empreendimentos}

\section{Empresa A e Empreendimento E1}

A Empresa A, com sede na cidade de Porto Alegre/RS, atua na construção e incorporação de empreendimentos residenciais de pequeno porte, incluindo condomínios de casas e prédios. A empresa já tinha um sistema de PCP formalizado, o qual possuía elementos do LPS, sendo o mesmo dividido em níveis hierárquicos, com ênfase na identificação e remoção de restrições no nível de médio prazo.

Além disto, a empresa estava engajada em um processo de melhorias baseado nos princípios da Produção Enxuta com apoio de uma empresa de consultoria. Assim, empresa tinha interesse em implementar melhorias no PCP a partir da definição de zonas de trabalho e do apoio de BIM.

O Empreendimento E1 era um condomínio residencial com área total construída de 113.360 m², localizado na cidade de Porto Alegre/RS, e composto por 99 casas de 2 e 3 dormitórios divididos em três fitas (Figura 4). As casas possuíam 5 tipologias diferentes, com áreas que variavam de 155 a $210 \mathrm{~m}^{2}$. Este estudo ocorreu numa etapa intermediária da obra, na qual diversos serviços ainda estavam sendo executados.

\section{Empresa B e Empreendimento E2}

A Empresa B, com sede na cidade de Canoas/RS, atua na construção e incorporação de empreendimentos com uma elevada quantidade de unidades e repetitividade. A empresa tinha um sistema de PCP formalizado, que possuía elementos do LPS, mantinha constantemente programas de melhorias gerenciais e se interessou em melhorar o sistema de PCP com base na abordagem baseada em zonas de trabalho.

O Empreendimento E2 era um condomínio residencial multifamiliar, localizado na cidade de Canoas/RS, em um terreno de área de 8.887,65 m². O condomínio era composto por 150 apartamentos, divididos em 5 torres com 5 pavimentos cada, sendo 6 apartamentos de $49 \mathrm{~m}^{2}$ por andar, com duas tipologias distintas. Este estudo ocorreu numa etapa inicial de execução da obra, sendo que o modelo BIM do Empreendimento E2 já estava desenvolvido. Logo, foi possível acompanhar a execução dos serviços iniciais, principalmente relacionados às torres A e B. A entrega da obra foi dividida em fases: primeiramente deveriam ser entregues as torres A e $\mathrm{B}$, seguidas respectivamente pelas torres C, D e E, uma após a outra (Figura 5).

\section{Fontes de evidência utilizadas}

Em ambos os estudos foram utilizadas múltiplas fontes de evidência, visando a permitir a triangulação entre as mesmas, incluindo entrevistas, observação participante, observação direta e análise de documentos. O Quadro 1 e o Quadro 2 apresentam as fontes de evidências, seus objetivos e e o tempo dispendido em entrevistas, visitas e reuniões, para cada uma das fases dos Estudo Empírico 1 e Estudo Empírico 2, respectivamente.

\section{Resultados e discussões \\ Estudo Empírico 1}

Inicialmente, foram identificados os potenciais usuários do modelo BIM 4D do Empreendimento E1, por meio de uma entrevista com os diferentes intervenientes envolvidos no PCP e na obra. O desenvolvimento do modelo foi realizado de forma progressiva. Em um primeiro momento, alguns espaços foram modelados com LOD 100, a fim de apenas representar o volume das edificações e a localização das mesmas. Ao longo do estudo o modelo foi detalhado, chegando a LOD 200 e 300. 


\section{Figura 3 - Delineamento da pesquisa}

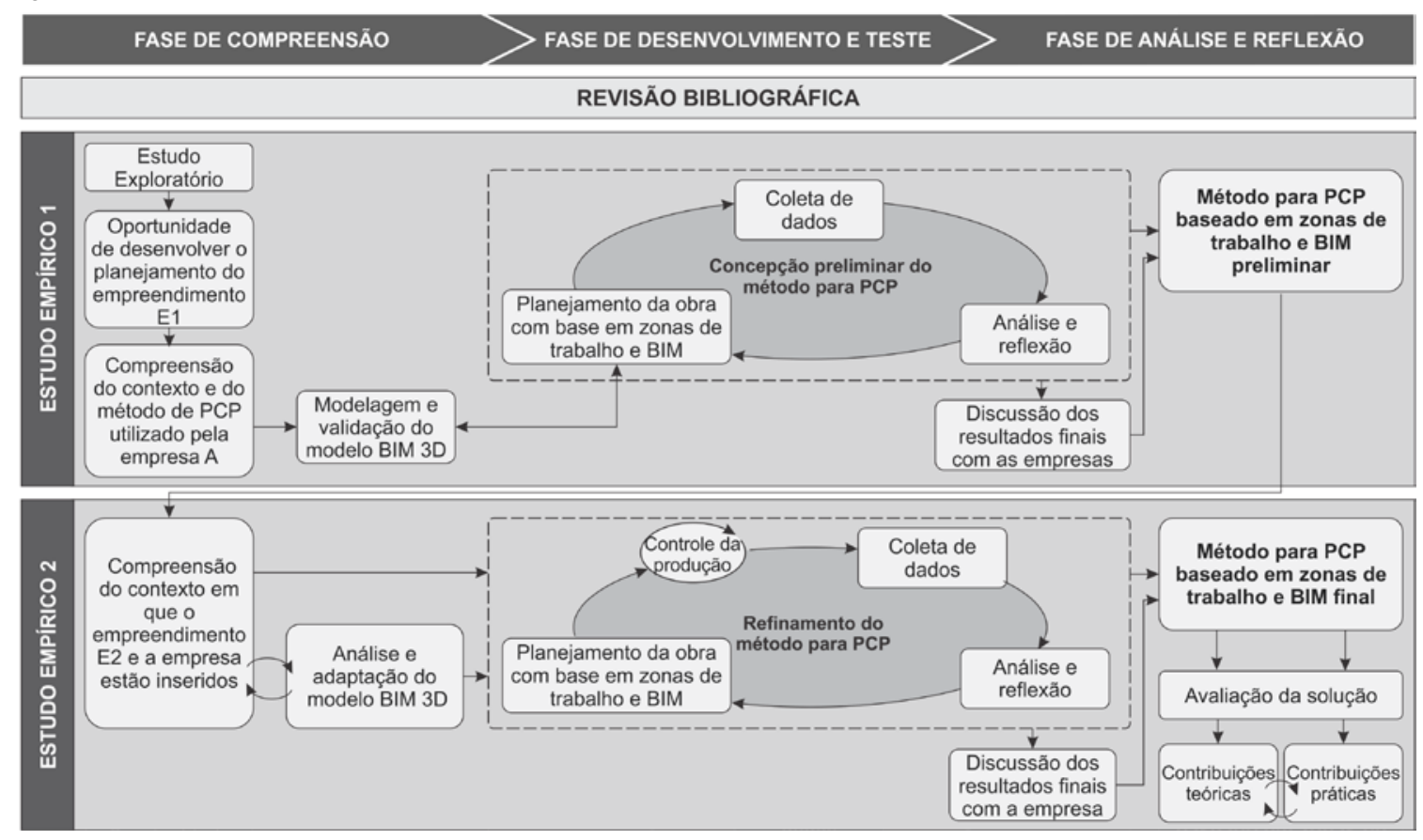

\section{Figura 4 -Empreendimento E1}

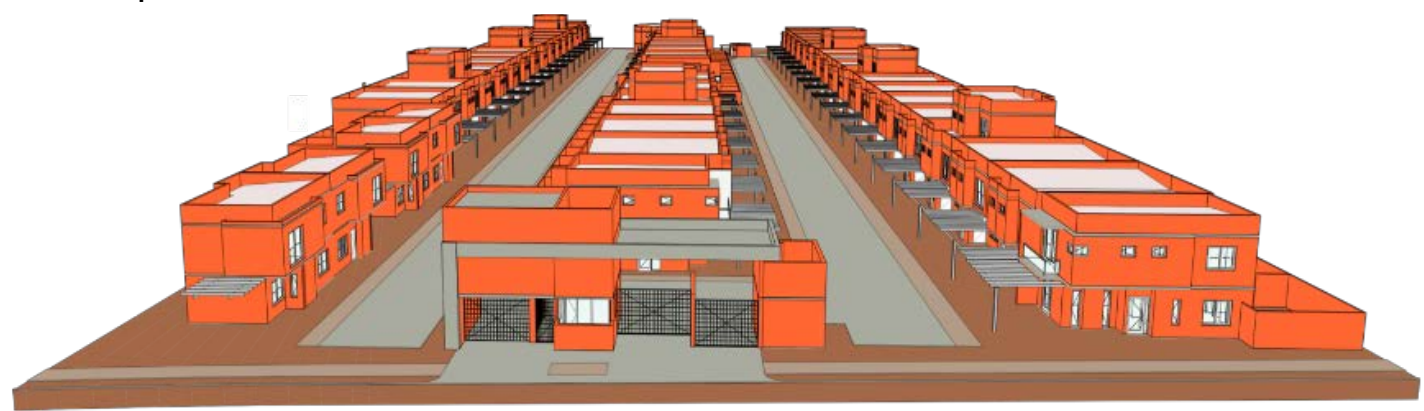

Figura 5 - Entrega em fases do Empreendimento E2

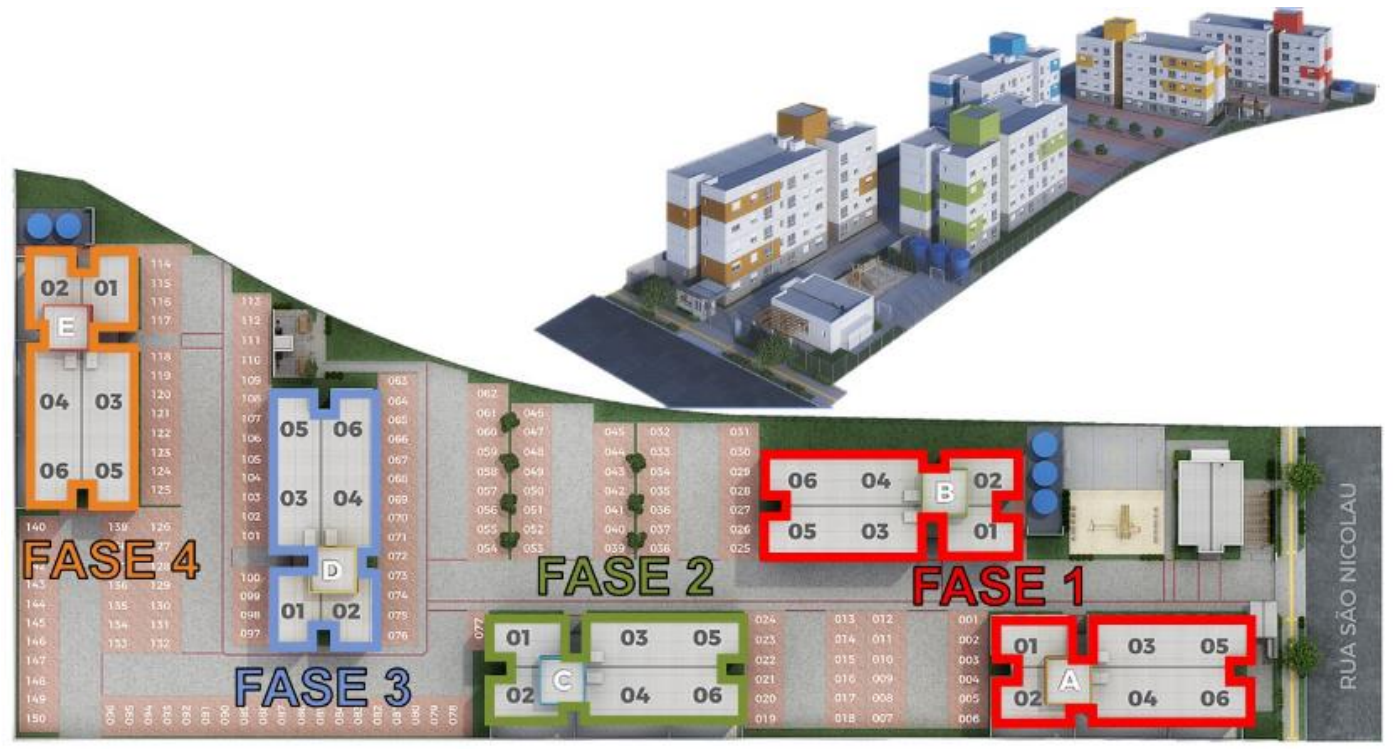


Quadro 1 - Fontes de evidência utilizadas no Estudo Empírico E1

\begin{tabular}{|c|c|c|c|}
\hline \multirow{2}{*}{ Fase } & \multirow{2}{*}{ Ações e Fontes de Evidência } & \multicolumn{2}{|r|}{ Estudo Empírico E1 (Empresa A) } \\
\hline & & Duração & \begin{tabular}{|c|} 
Objetivo \\
\end{tabular} \\
\hline \multirow{5}{*}{$\begin{array}{l}\text { COMPREENSÃO } \\
\text { (DIAGNÓSTICO) }\end{array}$} & $\begin{array}{c}\text { Reuniões iniciais com a empresa } \\
\text { (Observações Participantes) }\end{array}$ & $\begin{array}{l}2 \text { reuniões } \\
(2 \mathrm{~h})\end{array}$ & $\begin{array}{l}\text { Compreensão inicial das necessidades e } \\
\text { dificuldades enfrentadas pela empresa. }\end{array}$ \\
\hline & $\begin{array}{c}\text { Reuniões de médio e curto prazo } \\
\text { (Observações participantes) }\end{array}$ & $\begin{array}{l}3 \text { reuniões } \\
\text { (1h30min) }\end{array}$ & $\begin{array}{l}\text { Verificar a atuação dos diferentes } \\
\text { participantes, os principais problemas } \\
\text { enfrentados, e como era feito o PCP, } \\
\text { incluindo a utilização de indicadores. }\end{array}$ \\
\hline & $\begin{array}{c}\text { Visitas ao canteiro de obras } \\
\text { (Observações diretas e registros } \\
\text { fotográficos) }\end{array}$ & $\begin{array}{l}2 \text { visitas } \\
(2 \mathrm{~h})\end{array}$ & $\begin{array}{l}\text { Verificar o leiaute do canteiro de obras e } \\
\text { o andamento da obra. }\end{array}$ \\
\hline & $\begin{array}{c}\text { Entrevistas abertas } \\
\text { (Estudo Empírico 1) } \\
\text { Entrevistas semi-estruturadas } \\
\text { (Estudo Empírico 2) }\end{array}$ & $\begin{array}{l}2 \text { entrevistas } \\
\text { com } \\
\text { consultores } \\
(2 \mathrm{~h})\end{array}$ & $\begin{array}{l}\text { Compreender o processo de PCP da } \\
\text { empresa e os problemas enfrentados. }\end{array}$ \\
\hline & $\begin{array}{l}\text { Análise de documentos } \\
\text { fornecidos pela empresa }\end{array}$ & - & $\begin{array}{l}\text { Analisar os cronogramas, orçamento, } \\
\text { planilhas das reuniões de médio e curto } \\
\text { prazo, planilha de restrições, gráfico de } \\
\text { desvio de ritmo, indicadores, plano de } \\
\text { ataque, diagrama de precedência das } \\
\text { tarefas, definição dos lotes de produção } \\
\text { transferência. }\end{array}$ \\
\hline \multirow{5}{*}{$\begin{array}{l}\text { DESENVOLVIMENTO, } \\
\text { TESTE E REFLEXÃO }\end{array}$} & $\begin{array}{l}\text { Reuniões de médio prazo } \\
\text { (Observações Participantes) }\end{array}$ & $\begin{array}{l}5 \text { reuniões } \\
(2 \mathrm{~h})\end{array}$ & \multirow{3}{*}{$\begin{array}{l}\text { Acompanhamento da obra de uma forma } \\
\text { geral e discussão dos potenciais da } \\
\text { solução proposta. }\end{array}$} \\
\hline & $\begin{array}{c}\text { Reuniões de curto prazo } \\
\text { (Observações Participantes) }\end{array}$ & $\begin{array}{l}6 \text { reuniões } \\
(1 \mathrm{~h} 30 \mathrm{~min})\end{array}$ & \\
\hline & $\begin{array}{c}\text { Visitas ao canteiro de obras } \\
\text { (Observações diretas e registros } \\
\text { fotográficos) }\end{array}$ & $\begin{array}{l}7 \text { visitas } \\
\text { (1h) }\end{array}$ & \\
\hline & $\begin{array}{l}\text { Reuniões com consultores lean } \\
\text { (Observações Participantes) }\end{array}$ & $\begin{array}{l}8 \text { reuniões } \\
(1 \mathrm{~h})\end{array}$ & $\begin{array}{l}\text { Discutir e refletir sobre a implementação } \\
\text { do PCP baseado em zonas de trabalho e } \\
\text { BIM }\end{array}$ \\
\hline & $\begin{array}{c}\text { Reunião final } \\
\text { (Observação Participante) }\end{array}$ & 1 reunião $(3 h)$ & $\begin{array}{l}\text { Apresentação dos resultados finais do } \\
\text { estudo para a empresa. }\end{array}$ \\
\hline
\end{tabular}


Quadro 2 - Fontes de evidência utilizadas no Estudo Empírico E2

\begin{tabular}{|c|c|c|c|}
\hline \multirow{2}{*}{ Fase } & \multirow{2}{*}{ Ações e Fontes de Evidência } & \multicolumn{2}{|c|}{ Estudo Empírico E2 (Empresa B) } \\
\hline & & Duração & \begin{tabular}{|r|} 
Objetivo \\
\end{tabular} \\
\hline \multirow{5}{*}{$\begin{array}{l}\text { COMPREENSÃO } \\
\text { (DIAGNÓSTICO) }\end{array}$} & $\begin{array}{c}\text { Reuniões iniciais com a empresa } \\
\text { (Observações Participantes) }\end{array}$ & $\begin{array}{l}1 \text { reunião } \\
(2 \mathrm{~h})\end{array}$ & $\begin{array}{l}\text { Discutir os objetivos do estudo e } \\
\text { problemas enfrentados pela } \\
\text { empresa. }\end{array}$ \\
\hline & $\begin{array}{c}\text { Reuniões de médio e curto prazo } \\
\text { (Observações participantes) }\end{array}$ & $\begin{array}{l}3 \text { reuniões com o engenheiro de obra } \\
\text { responsável pelo PCP do } \\
\text { Empreendimento E2 (1h30min) }\end{array}$ & $\begin{array}{l}\text { Compreender o processo de PCP da } \\
\text { empresa e os problemas } \\
\text { enfrentados. }\end{array}$ \\
\hline & $\begin{array}{c}\text { Visitas ao canteiro de obras } \\
\text { (Observações diretas e registros } \\
\text { fotográficos) }\end{array}$ & $\begin{array}{l}2 \text { visitas } \\
(1 \mathrm{~h} 30 \mathrm{~min})\end{array}$ & $\begin{array}{l}\text { Verificar o leiaute do canteiro de } \\
\text { obras e o terreno que iria ser } \\
\text { construído o empreendimento. }\end{array}$ \\
\hline & $\begin{array}{c}\text { Entrevistas abertas } \\
\text { (Estudo Empírico 1) } \\
\text { Entrevistas semi-estruturadas } \\
\text { (Estudo Empírico 2) }\end{array}$ & $\begin{array}{l}1 \text { entrevista com os engenheiros de } \\
\text { obra e o arquiteto responsável pela } \\
\text { gestão de projetos da Empresa B ( } 2 \mathrm{~h} \text { ) } \\
1 \text { entrevista com o arquiteto } \\
\text { responsável pelo projeto em BIM e o } \\
\text { arquiteto responsável pela gestão de } \\
\text { projetos da Empresa B ( } 2 \mathrm{~h})\end{array}$ & $\begin{array}{l}\text { Compreender as técnicas, } \\
\text { ferramentas e o sistema de PCP } \\
\text { adotado na empresa. } \\
\text { Compreender como foi desenvolvido } \\
\text { o modelo BIM do empreendimento. }\end{array}$ \\
\hline & $\begin{array}{l}\text { Análise de documentos } \\
\text { fornecidos pela empresa }\end{array}$ & - & $\begin{array}{l}\text { Análisar projetos e documentos da } \\
\text { empresa (cronogramas, orçamento, } \\
\text { planilhas das reuniões de longo e } \\
\text { curto prazo, diagrama de } \\
\text { precedência das tarefas, indicadores, } \\
\text { definição dos lotes de produção e } \\
\text { transferência). }\end{array}$ \\
\hline \multirow{2}{*}{$\begin{array}{l}\text { DESENVOLVIMENTO, } \\
\text { TESTE E REFLEXÃO }\end{array}$} & $\begin{array}{l}\text { Reuniões com consultores lean } \\
\text { (Observações Participantes) }\end{array}$ & - & - \\
\hline & $\begin{array}{c}\text { Reunião final } \\
\text { (Observação Participante) }\end{array}$ & $\begin{array}{l}1 \text { reunião } \\
\text { (3h30min) }\end{array}$ & $\begin{array}{l}\text { Apresentação dos resultados finais } \\
\text { do estudo para a Empresa B. }\end{array}$ \\
\hline
\end{tabular}

Na sequência, para dividir o empreendimento em lotes para fins de PCP, o pesquisador e os consultores de planejamento da Empresa A definiram a EHZT do Empreendimento E1 com o auxílio do modelo BIM (Figura 6). Para facilitar tal divisão, foram utilizados o diagrama de precedência e o sequenciamento de execução da unidade base (casa). No segundo nível, os lotes foram definidos a partir das dimensões dos radiers, considerando a necessidade de balancear a quantidade de trabalho entre as equipes, sendo compostos de módulos de 6 ou 7 casas com ciclos de produção de uma semana ou múltiplos dessa. Os lotes definidos tinham como base as tarefas críticas, que podiam representar um gargalo para a produção e limitar a capacidade de produção de todo o sistema. No terceiro nível, foi realizada uma subdivisão dos módulos de casas em cada unidade habitacional para atender as necessidades de tamanhos lotes de produção de outras tarefas.

Em seguida, os elementos do modelo BIM foram categorizados em itens a fim de agrupá-los e vinculá-los aos componentes de custo. Estes componentes foram vinculados às tarefas definidas no plano e foram feitas as demais definições de planejamento para obter o plano de longo prazo, representado pela linha de balanço. Os consultores solicitaram a simulação de três planos de ataque para o empreendimento e definiram que o empreendimento seria executado em duas frentes de trabalho (Figura 7). A frente de trabalho 1 ficou encarregada de executar os lotes de casas A e B, e a frente de trabalho 2 os lotes C e D. O lote E e a infraestrutura dos acessos foram executados paralelamente aos demais lotes de casas.

Com base nisto, foi realizado o sequenciamento das zonas de trabalho, as vinculações das tarefas aos respectivos níveis da EHZT para definir os lotes de produção, e as definições das durações e do ritmo de 
produção das tarefas. A linha de balanço adotada como plano de longo prazo do Empreendimento E1 é apresentada na Figura 8, evidenciando que há duas frentes de trabalho concomitantes.

A visualização do fluxo de trabalho nas simulações 4D, por meio da manipulação do modelo e vídeos gerados, em conjunto com a linha de balanço, permitiram aos representantes da Empresa A compreender o plano de ataque da obra, identificar folgas presentes no plano e visualizar a sincronização das tarefas. Isto ficou evidente no decorrer das reuniões e a partir das impressões da equipe envolvida. Na Figura 9 as atividades foram destacadas por diferentes cores, as quais evidenciam os lotes de produção em andamento em uma determinada semana. Os consultores e demais representantes da Empresa A apontaram que estas imagens, extraídas das simulações 4D do empreendimento, possuíam grande potencial para serem utilizadas em um dispositivo visual, a fim de disseminar os planos de forma mais clara, permitindo maior compreensão e acesso à informação.

\section{Figura 6 - Níveis da EHZT do Empreendimento E1}

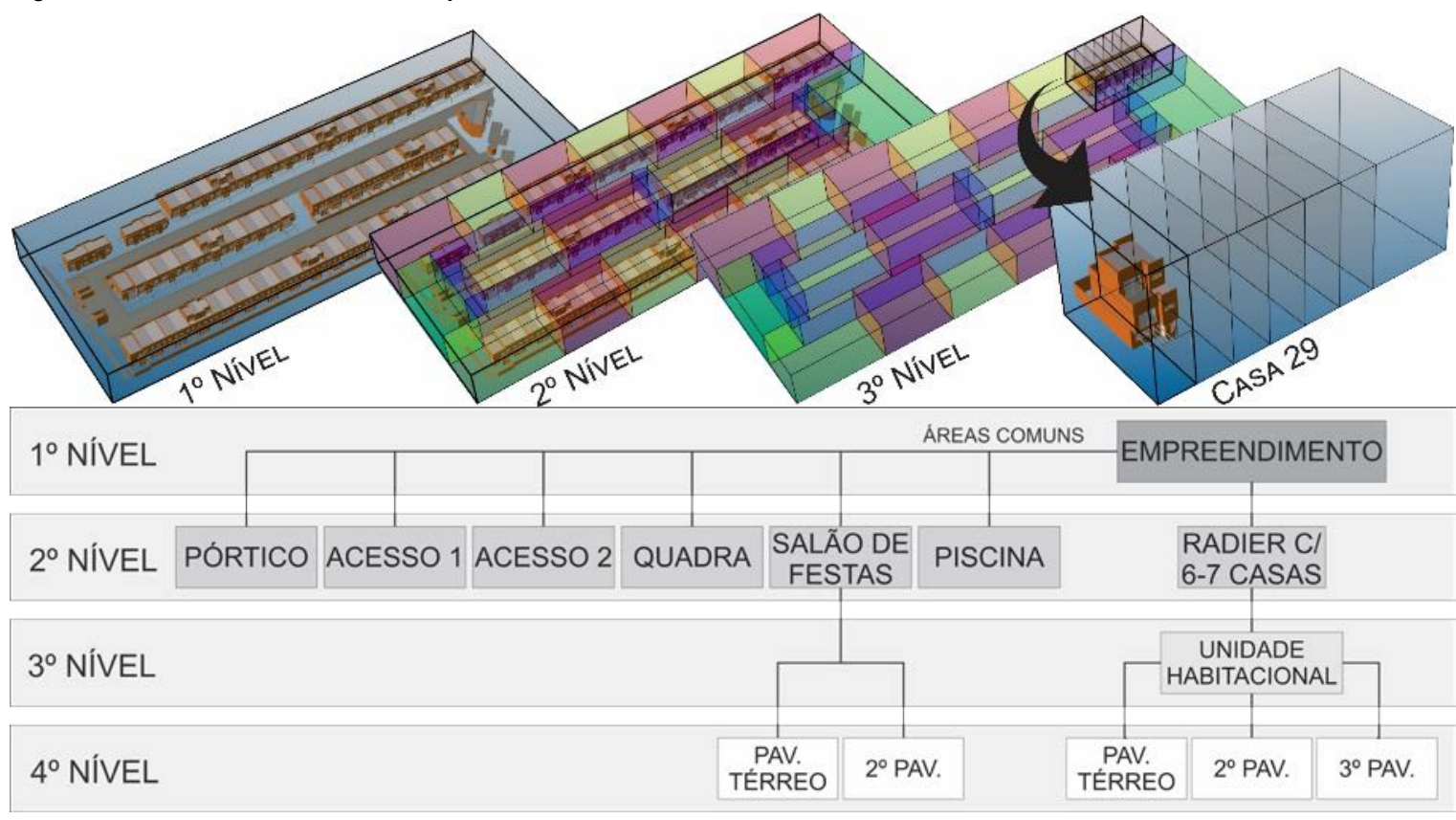

Figura 7 - Implantação do empreendimento, divisão dos lotes e diferentes frentes de trabalho

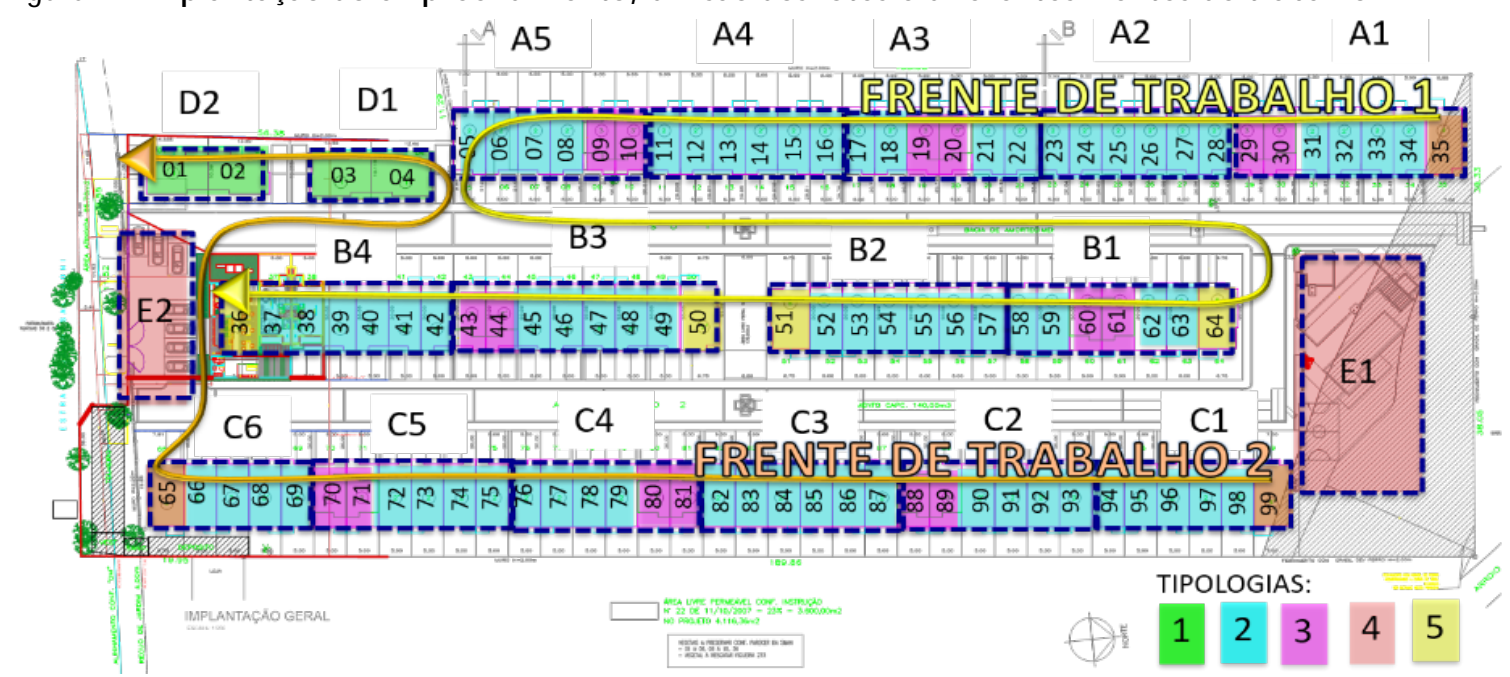

Fonte: adaptado da Empresa A. 
Figura 8 - Linha de balanço do Empreendimento E1

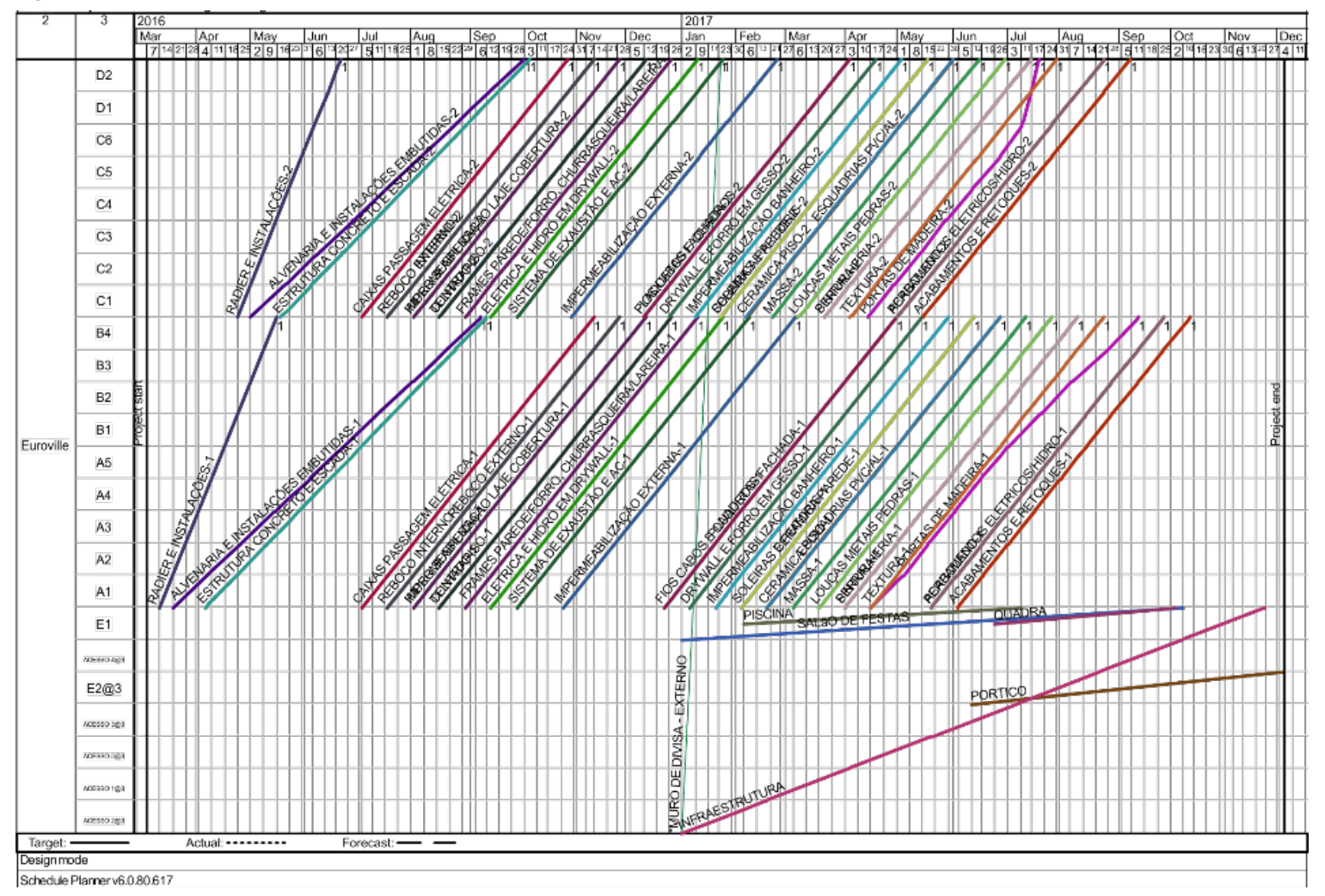

Em relação as reuniões de médio prazo, foi possível identificar restrições relacionadas a execução do sistema de drenagem, esgoto e de outros projetos complementares. Nestas reuniões, a visualização do modelo BIM evidenciou o baixo detalhamento dos projetos e gerou a necessidade de melhor detalhamento dos mesmos a fim de permitir que estes serviços fossem planejados.

Devido ao esforço da equipe de pesquisa demandado ao longo do desenvolvimento do plano no software Vico Office, o controle da produção do empreendimento ficou de fora do seu escopo e a obra foi apenas monitorada. Apesar do software permitir avaliar rapidamente alternativas ao plano, as vinculações entre os elementos do modelo BIM, os componentes de custos e as tarefas do plano demandaram bastante tempo. O software apresenta diversas ferramentas, necessita diversos dados de entrada e possui uma lógica própria, o que, inicialmente, tornou difícil a elaboração da linha de balanço.

Por outro lado, a captação inicial das necessidades dos usuários do modelo 4D, relacionadas principalmente à compreensão dos fluxos do produto e de trabalho das equipes, contribuiu para evitar o detalhamento desnecessário do modelo BIM e fez com que se tivesse atenção ao desenvolver os elementos do modelo, os quais foram organizados em diferentes tipologias, layers e materiais. Isto impactou positivamente na categorização dos itens, reduzindo o tempo dispendido para realocar e reagrupar os elementos para vincular aos componentes de custo e às tarefas.

\section{Estudo Empírico 2}

O modelo BIM do Empreendimento E2, previamente desenvolvido em LOD 200 e 300, foi analisado, adaptado e utilizado com a finalidade de auxiliar as decisões iniciais de planejamento. Com apoio do modelo, um dos autores e o engenheiro de obras propuseram a divisão da EHZT (Figura 10), com base em lotes de produção e de transferência, conforme sugerido por Schramm (2009). No primeiro nível, a obra foi inicialmente dividida por torres e áreas comuns. Em um segundo nível, as torres foram subdivididas em área interna e externa. A área interna foi subdividida verticalmente em pavimentos para atender as tarefas iniciais das torres, tais como a estrutura de concreto e alvenaria. Cada um destes pavimentos foi subdividido horizontalmente em apartamentos para atender as tarefas de acabamento internas, e a parte externa foi subdividida horizontalmente em planos de fachada (norte, sul, leste e oeste). 
Figura 9 - Simulação 4D que mostra as atividades que estarão em andamento em determinada semana

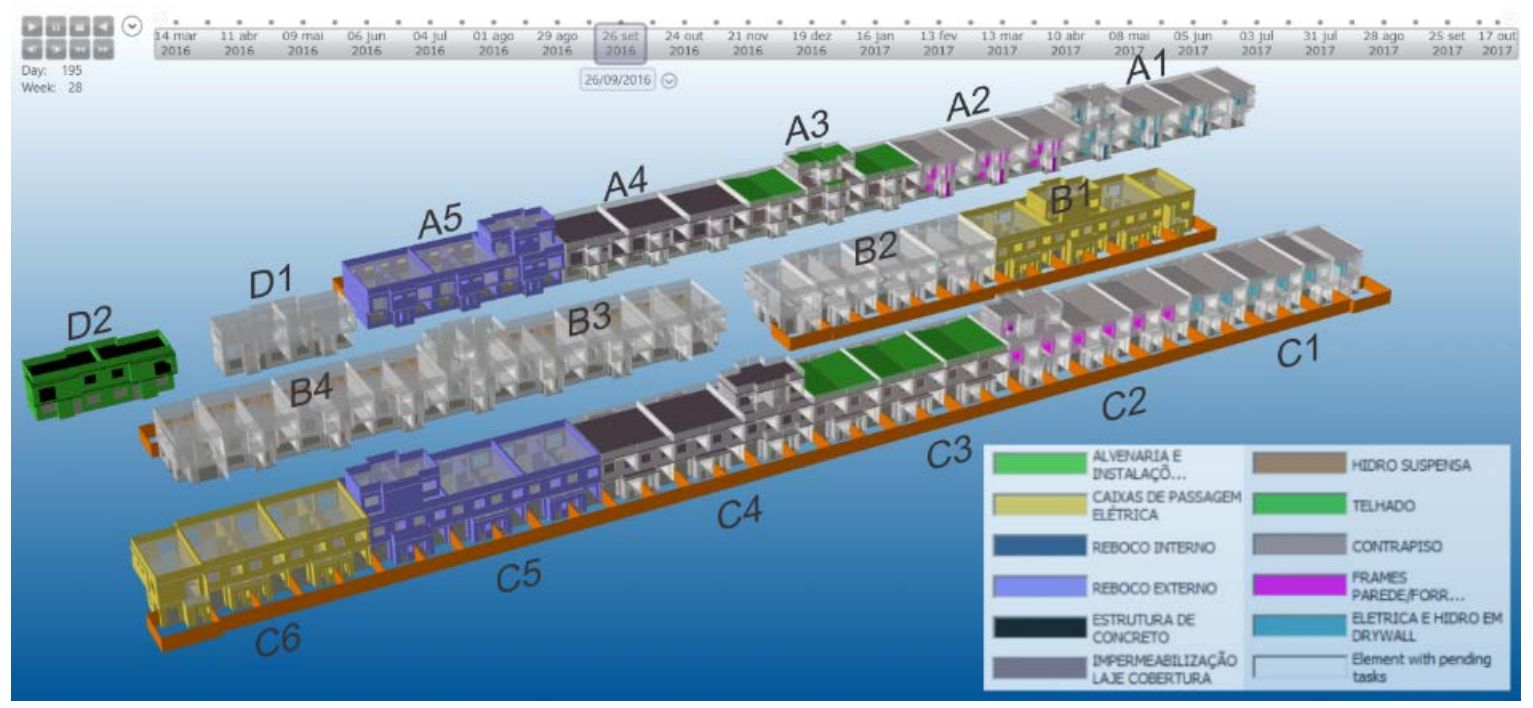

Figura 10 -Parte da EHZT do Empreendimento E2, com ênfase ao pavimento térreo da torre A

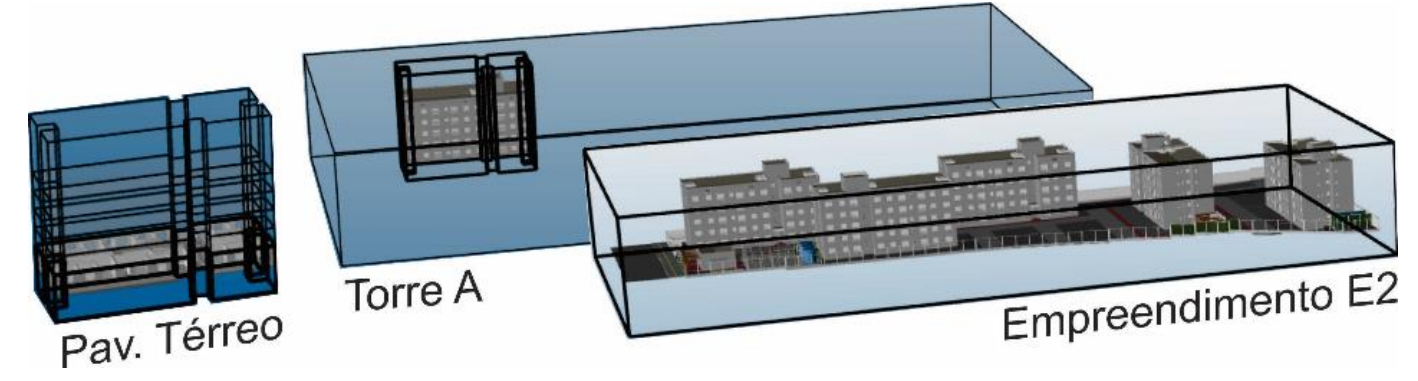

Ao analisar a estrutura de custos da empresa, constatou-se que o grau de agregação da mesma era incompatível com as tarefas a serem planejadas. Como era necessário alterar a estrutura de custos a fim de associar os componentes de custo à uma tarefa, decidiu-se, em conjunto com o engenheiro de obra, desenvolver o modelo 4D de forma independente ao orçamento. Assim, com a participação do engenheiro de obra, foi definido o diagrama de precedência, com base no sequenciamento padrão para as tarefas (relações lógicas), foram estimados o tempo de execução e os ritmos de produção. Também foi definida a sequência de execução das zonas de trabalho, sendo alocadas as tarefas em um nível da EHZT para definir o tamanho dos lotes de produção. Por questões de logística e contratação, as fundações, e as redes de água e esgoto subterrâneas de todas as torres foram consideradas como um grande lote, enquanto os demais serviços foram planejados primeiramente para as torres A e B de forma alternada, seguidas pelas torres C, D, e E, com uma defasagem de tempo entre si.

Ao longo do estudo foi identificada uma forte interdependência do Empreendimento E2 com outro empreendimento da empresa que estava em etapas mais avançadas de execução (Figura 11). O segundo empreendimento possuía dois jogos de formas para a execução das lajes, sendo que um dos jogos estava destinado para executar as torres A e B do Empreendimento E2, e o outro jogo para executar as torres C e D. A torre E estava planejada para ser executada após a finalização das torres A e B.

Então, as simulações 4D do empreendimento foram analisadas para definir o plano de longo prazo, representado por uma linha de balanço. Este plano, além de atender ao cronograma de entrega das torres considerando as fases da obra, precisaria atender às interdependências identificadas entre os empreendimentos e entre as torres.

Além disto, a simulação foi utilizada para definir a quantidade de equipes e jogos de formas necessários para atender ao cronograma. O foco maior foi dado às tarefas de execução de alvenaria e lajes, visto que estas puderam ser monitoradas durante o estudo, sendo que atrasos das mesmas afetavam diretamente o prazo de entrega das torres, e ambas eram interdependentes e precisavam ser executadas alternadamente em cada torre. Uma análise similar a esta foi realizada por Schramm (2009). 
Figura 11 - Interdependência entre diferentes empreendimentos da Empresa B

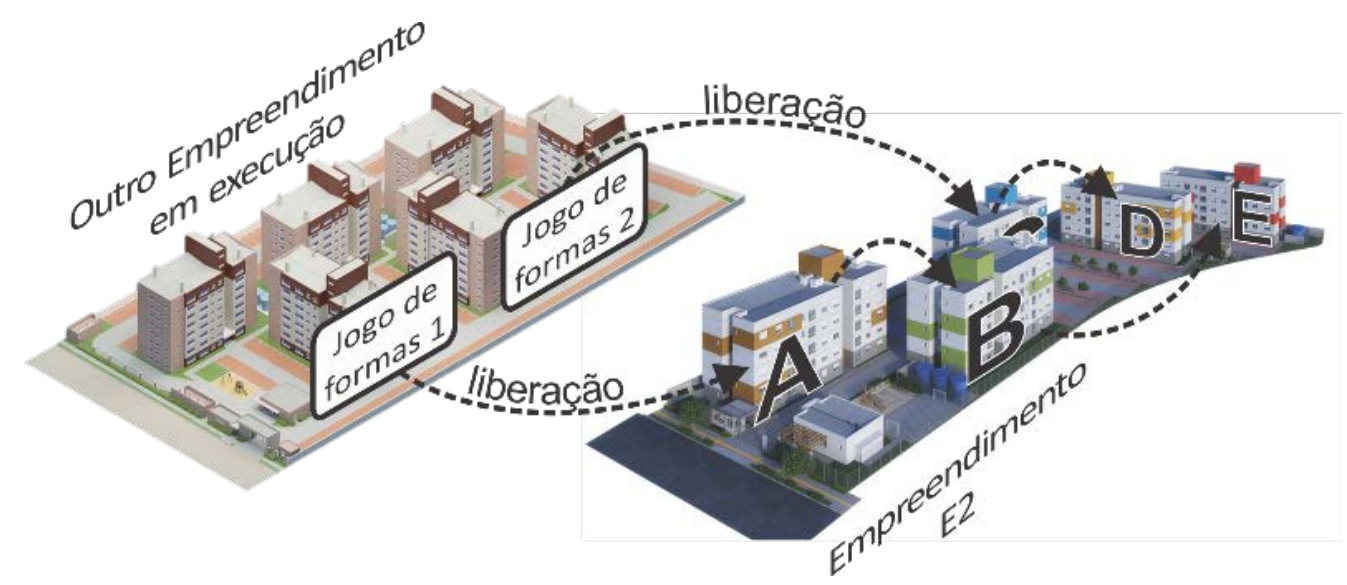

Nas 6 simulações realizadas foi possível solucionar alguns problemas identificados no plano:

(a) as alvenarias estavam sendo executadas ao mesmo tempo que as lajes nas torres A e B;

(b) os tempos de ciclo da execução das alvenarias e lajes estavam desbalanceados, evidenciados pela ociosidade representada por cores na simulação 4D (Figura 12) e na linha de balanço;

(c) a contratação de mais uma equipe para cada uma das atividades de um conjunto de torres gerava ociosidade;

(d) apenas uma equipe e um jogo de formas para executar todas as torres não era suficiente para atender ao cronograma de entrega das torres $\mathrm{C}$ e E; e

(e) um terceiro jogo de formas alugado era inviável do ponto de vista econômico.

Na simulação adotada para o plano, o balanceamento das tarefas de alvenaria e lajes foi realizado a partir de dados do outro empreendimento da Empresa B. A alvenaria de um apartamento era executada a cada dois dias, e o tempo de execução de um pavimento foi reduzido de 17 para 12 dias, sincronizando algumas atividades (Figura 12). Ainda, as atividades de reboco externo, azulejos e revestimento de gesso passaram a contar com apenas uma equipe para executá-las, sendo que o cronograma sofreu pequenas alterações em termos de prazos, sem comprometer a entrega das torres.

Em virtude deste estudo ter sido realizado nas etapas iniciais da obra, foi acompanhado o controle das atividades relacionadas à fundação, contrapiso, alvenaria e lajes. Nas reuniões semanais de curto prazo, foi utilizado o quadro de controle (Figura 13) em conjunto com o modelo 4D e a linha de balanço, os quais tornaram a etapa de controle mais fácil de ser compreendida e permitiram visualizar o andamento da obra. Este quadro permitiu identificar, por meio de cores, o status de cada uma das atividades nas respectivas zonas de trabalho, bem como suas datas de início e fim planejadas e reais. Nesta etapa do estudo, o modelo 4D permitiu visualizar por meio de cores o sequenciamento e o plano de ataque, e a linha de balanço permitiu explicitar o fluxo de trabalho, buffers, possíveis interferências e o impacto dos atrasos das tarefas. As três ferramentas em conjunto facilitaram a compreensão e discussão dos planos com o engenheiro de obra, estagiários responsáveis pelo acompanhamento da obra e demais funcionários que coordenavam as atividades no canteiro de obras.

Por fim, foi constatado que o ritmo de produção ainda estava sendo ajustado. No terceiro ciclo de alvenaria e lajes houve uma redução de 12 para 10 dias, resultado do processo de aprendizagem relacionado ao processo construtivo. Ainda, foi identificado e controlado o atraso das atividades iniciais, que não trouxe prejuízos aos prazos estabelecidos e nem às demais atividades.

\section{Método para planejamento e controle da produção baseado em zonas de trabalho com o apoio de BIM}

O método é composto por cinco macrofases, que são integradas, iterativas e foram representadas por cores distintas (Figura 14). Como observado nos estudos, as macrofases de suporte fornecem informações e contribuem ao PCP, que é a principal macrofase do método. Cada uma destas é descrita na sequência e esquematizada na Figura 15. 
A primeira macrofase consiste no desenvolvimento do modelo BIM, que deve ocorrer ao longo do projeto do empreendimento. Nesta macrofase, grande parte da informação utilizada para a gestão de custos e para 0 planejamento é gerada. Logo, para que a informação seja confiável na etapa de PCP, os elementos devem ser modelados com um nível de desenvolvimento apropriados. Conforme observado nos estudos, a captação das necessidades das equipes de custos e planejamento, referente ao grau de detalhamento do plano e do orçamento necessários, e as necessidades advindas dos software utilizados permite de forma colaborativa tomar decisões a respeito das informações a serem inseridas no modelo. Com isso, é possível definir critérios de modelagem, desenvolver ou adaptar um modelo BIM, e exportá-lo para software próprio para planejamento.

A segunda macrofase diz respeito à definição da EHZT a partir do modelo BIM. Esta é fundamental para o processo de PCP, visto que as subdivisões sucessivas do empreendimento em zonas menores servem para definir o tamanho dos lotes de produção e transferência das tarefas. Logo, busca-se definir pequenos lotes de produção, visando a reduzir o tempo de ciclo dos processos, gerar um maior efeito aprendizado e facilitar o controle da produção (KOSKELA, 2000). Conforme observado nos estudos, as zonas de trabalho devem ser espacialmente bem definidas e permitir que tanto os elementos do modelo BIM, como os quantitativos e as atividades que agregam valor sejam subdivididos e alocadas nelas.

\section{Figura 12 - Balanceamento das atividades evidenciada pelos fluxos das equipes}

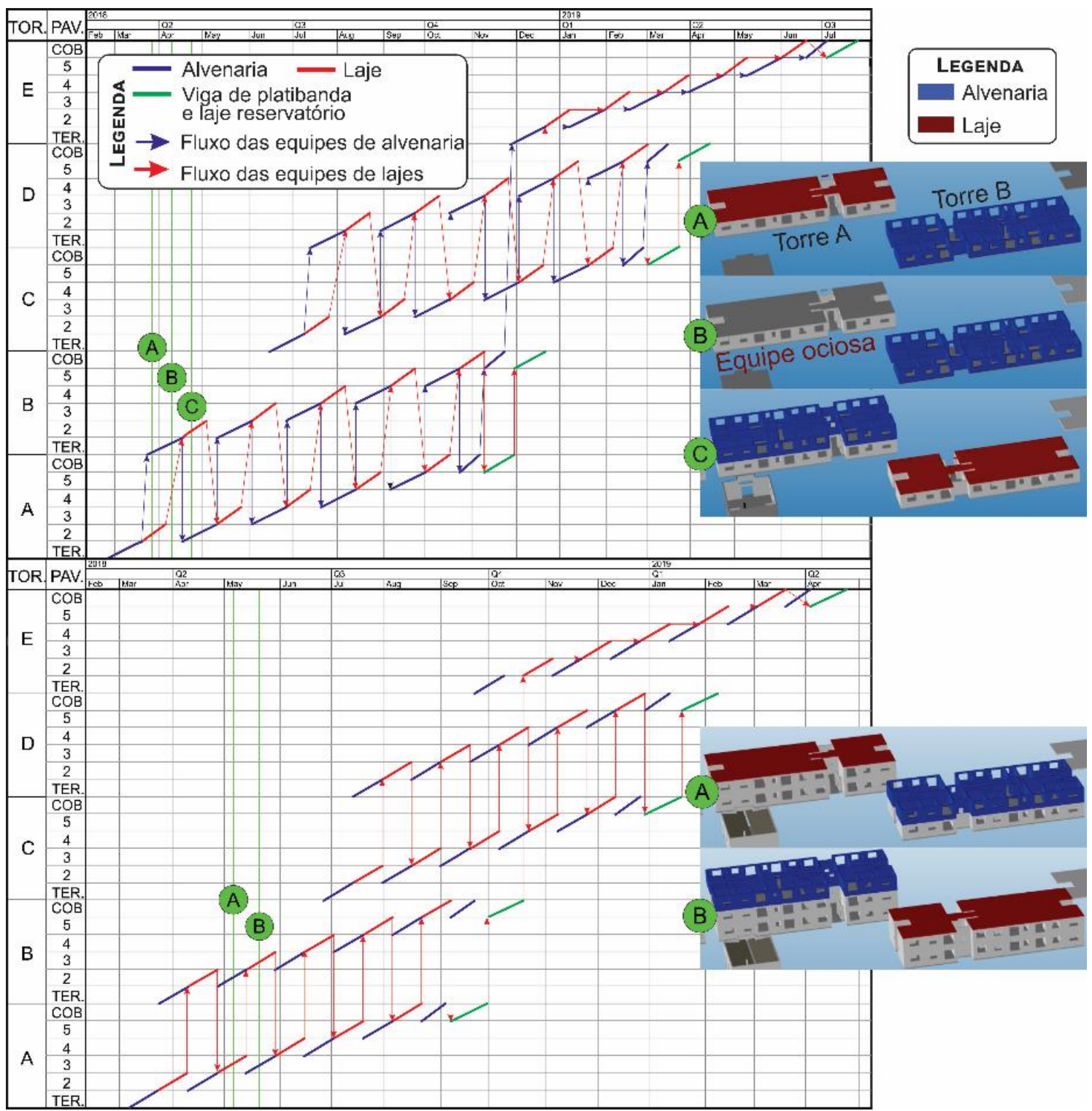


Figura 13 - Parte do quadro de controle visual

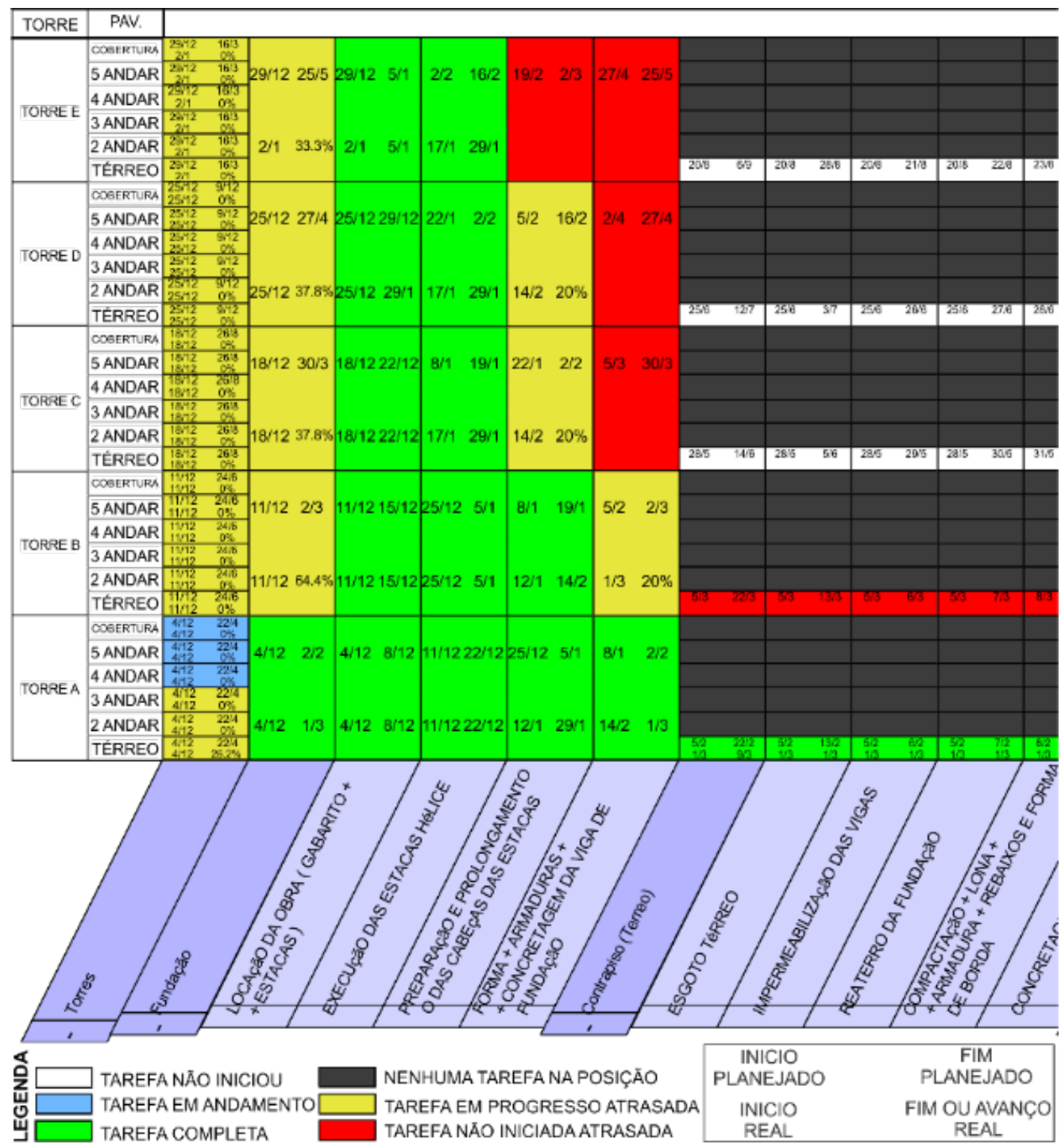

Figura 14 - Macrofases do método

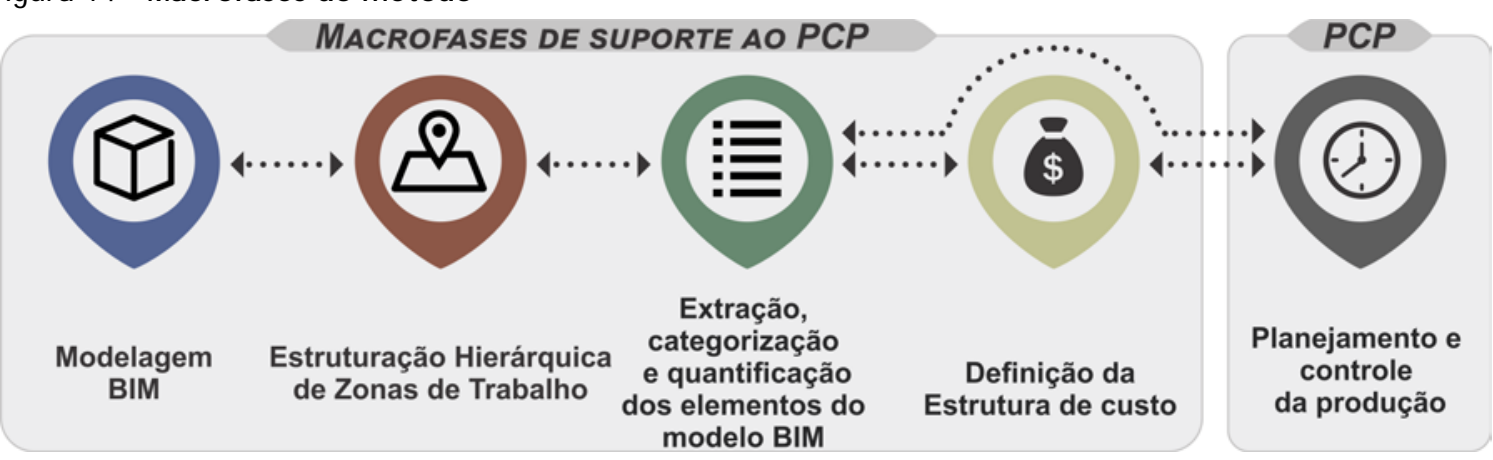


Figura 15 - Método para PCP baseado em zonas de trabalho e BIM

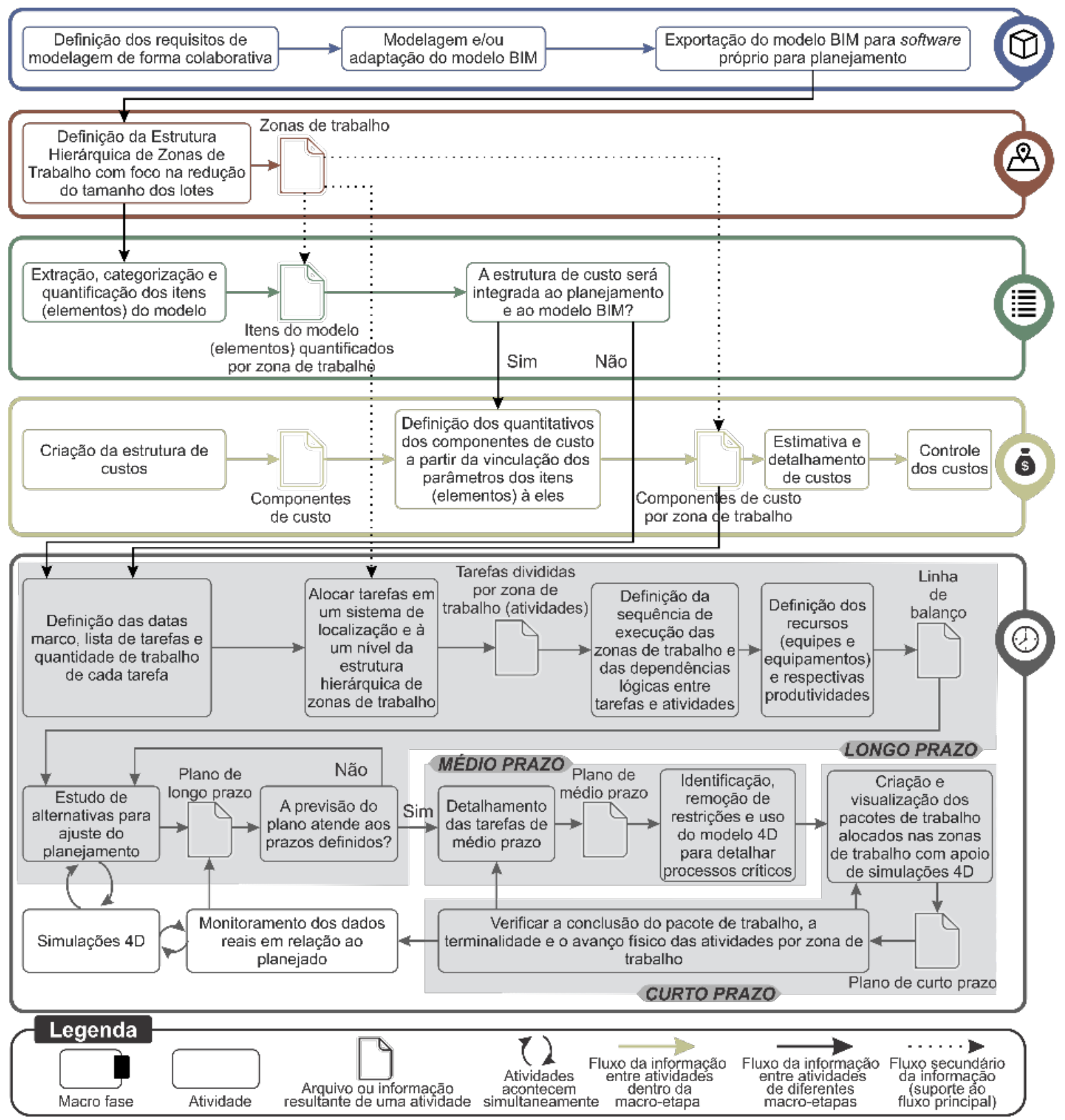

A terceira macrofase consiste na extração, categorização e quantificação dos elementos do modelo BIM. O objetivo é viabilizar a integração dos elementos modelo BIM com os componentes de custo e as tarefas. Logo, os elementos são organizados, agrupados em itens (grupos de elementos com característica similares) e tem seus parâmetros, como volume e área, quantificados. Ao longo dos estudos, a visualização da associação dos elementos do modelo BIM aos itens facilitou tal vinculação, por meio da visualização.

A quarta macrofase refere-se à criação da estrutura de custos. Caso seja integrada a modelagem 4D e 5D (custos), é realizada a vinculação dos parâmetros dos itens do modelo aos componentes de custo, e estes às tarefas do planejamento. Caso o custo não seja integrado, os parâmetros dos itens são vinculados diretamente às tarefas. Cabe investigar mais a fundo a subdivisão dos componentes de custo por zona de trabalho, visto que algumas parcelas dos custos, tal como itens dos custos indiretos, podem não ser facilmente relacionadas a zonas de trabalho. Por fim é possível estimar, detalhar e controlar os custos em cada uma das zonas de trabalho.

A quinta macrofase é o PCP propriamente dito. As decisões tomadas nesta macrofase, no nível de longo prazo, são similares a algumas decisões que fazem parte do Projeto do Sistema de Produção (PSP), conforme sugerido 
por Schramm (2009). Primeiro, deve-se definir datas marco de projeto, como o prazo final e entregas parciais, turnos de trabalho e a lista de tarefas, que devem atender aos níveis de detalhe do plano. Para definir a quantidade de trabalho (em horas) de cada uma das tarefas multiplica-se o quantitativo, definido pelo parâmetro do item, pelo consumo estimado de horas para executar uma unidade de medida definida $(0,5$ horas $/ \mathrm{m}^{3}$ por exemplo). A partir da quantidade de trabalho, deve-se verificar o tempo máximo de execução disponível e assim dimensionar a equipe. Neste ponto, é importante definir o ritmo de produção e o tempo de ciclo das tarefas de forma que os prazos sejam atendidos.

Na sequência, os lotes de produção são estabelecidos alocando as tarefas em um nível da EHZT. Deve-se buscar reduzir o tamanho dos lotes, objetivando o aumento da repetitividade, do efeito aprendizado e do controle logístico do canteiro de obras. Posteriormente, deve ser determinado o sequenciamento padrão das zonas de trabalho, buscando reduzir atividades de fluxo, descontinuidades das equipes e facilitar o sequenciamento das atividades que acontecem em diferentes zonas de trabalho. Este, além de ordenar o eixo vertical da linha de balanço, contribui no estabelecimento das dependências lógicas entre tarefas. Estas dependências devem seguir um diagrama de precedência e permitem definir os lotes de transferência. Por fim os recursos (equipes e equipamentos) são definidos e suas produtividades estimadas, bem como devem ser definidos os produtos resultantes da simulação necessários, podendo ser vídeos, snapshots (registros instantâneos de por meio de uma imagem), ou a manipulação do modelo 4D em tempo real.

Com a linha de balanço definida, são analisadas alternativas para refinar o plano de longo prazo com o auxílio de simulações 4D, podendo estar relacionadas a:

(a) logística e fluxos do canteiro de obras;

(b) sequenciamento das zonas de trabalho;

(c) ajuste da quantidade de recursos, do ritmo e balanceamento do tempo de ciclo das tarefas;

(d) possíveis interferências, necessidade de interromper o fluxo e sobrepor a produção em diferentes zonas de trabalho;

(e) necessidade de buffers de tempo ou de zonas de trabalho entre tarefas; e

(f) atendimento aos prazos definidos, ao fluxo de caixa e o total efetivo da obra.

No horizonte de médio prazo, as tarefas são detalhadas, as restrições relacionadas às tarefas e zonas de trabalho são identificadas, analisadas e removidas por um responsável designado. O plano de médio prazo pode demandar o detalhamento ou a modificação do modelo 4D a fim de realizar mudanças necessárias ou obter informações referentes ao detalhamento de um processo crítico a ser executado. Ainda, parte do processo de análise de restrições pode ser passada para o ciclo de produção. No estudo realizado por Bataglin et al. (2018), a confirmação da produção dos componentes pré-fabricados era realizada de acordo com a demanda de componentes específicos pela obra com quinze dias de antecedência. No mesmo estudo, a entrega era programada com dois dias de antecedência com base nas zonas de trabalho disponíveis para montagem.

No plano de curto prazo, devem ser definidos pacotes de trabalho semanais que tiveram suas restrições removidas. Estes pacotes semanais são alocados em zonas de trabalho disponíveis, visualizados e comunicados às equipes responsáveis por meio de imagens extraídas de simulações 4D. A verificação da disponibilidade dos recursos permite limitar a quantidade de trabalho em progresso existente.

Por fim, a análise e comparação de dados planejados e reais, provenientes do monitoramento dos planos de curto, médio e longo prazo, permitem que medidas corretivas sejam implementadas e estudos de novas alternativas sejam realizados. Desta forma, busca-se melhorar o desempenho dos planos e atingir as metas definidas. Esta comparação pode contar com o apoio de simulações $4 \mathrm{D}$ e da linha de balanço, as quais permitem realizar uma análise visual, e podem fornecer indicadores para medir o desempenho dos ciclos de PCP.

Destaca-se neste trabalho a utilização do indicador de terminalidade, que envolve o monitoramento da conclusão com qualidade dos pacotes de trabalho planejados, ao longo dos ciclos de controle, a partir de um quadro de controle visual (Figura 16). 
Figura 16 - Quadro para monitoramento do indicador de terminalidade

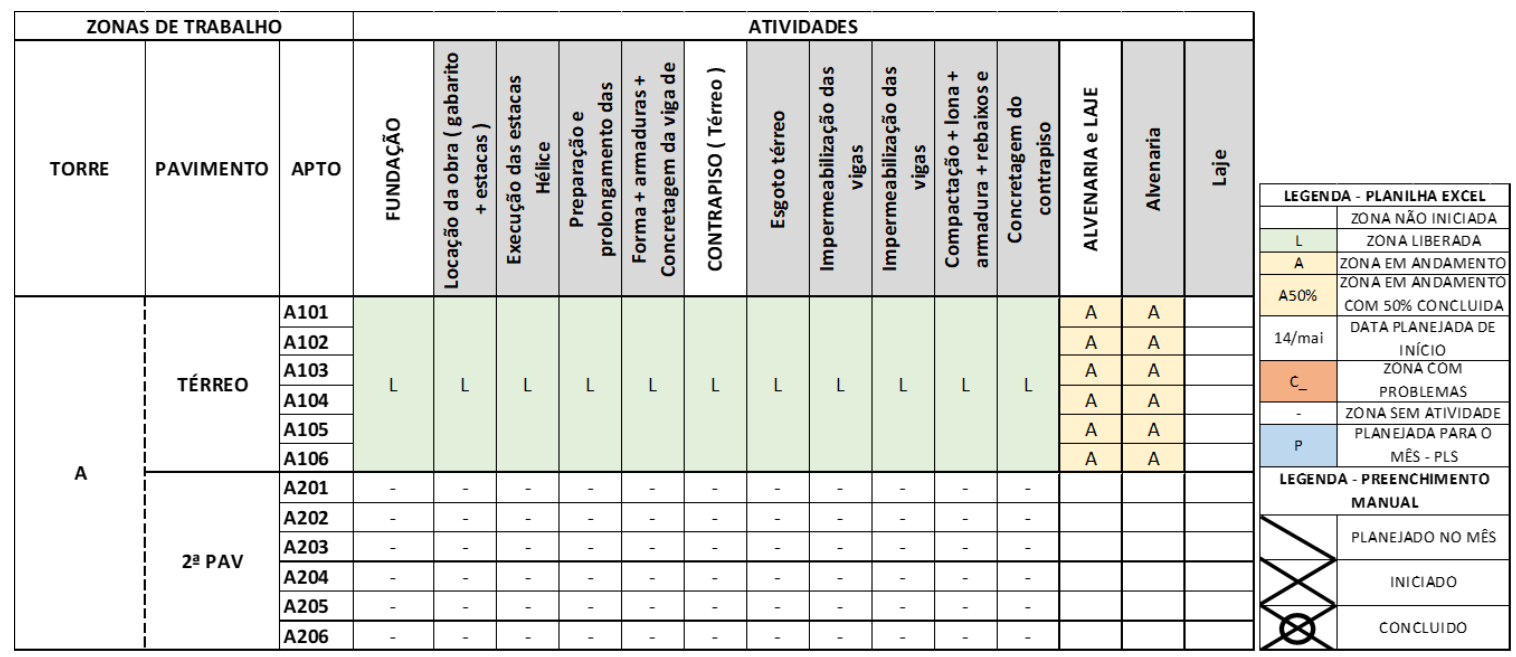

Diferentemente do Percentual de Pacotes Concluídos (PPC), o indicador de terminalidade permite acompanhar a falta de terminalidade das zonas de trabalho e suas causas específicas de uma forma sistemática, permitindo visualizar os locais nos quais tarefas posteriores iniciaram sem que as anteriores fossem finalizadas. O indicador de terminalidade é calculado pela relação, em porcentagem, entre o total de atividades com falta de terminalidade e o total de atividades em andamento (Equação 1). Este indicador também pode ser analisado sob a perspectiva das zonas de trabalho ao invés das atividades, podendo ser calculada a relação entre as zonas de trabalho com falta de terminalidade e as zonas em andamento.

Indicador de terminalidade $(\%)=100-\left(\frac{\text { atividades com falta de terminalidade }}{\text { atividades em andamento }}\right) \times 100$

Eq. 1

\section{Conclusão}

O presente estudo propôs um método de PCP baseado em zonas de trabalho com o apoio de BIM. A principal contribuição deste método foi a definição de um conjunto de passos que permite a integração do PCP baseado em zonas de trabalho com o LPS, com o uso de modelos BIM 4D. Isto permitiu que as porções do trabalho fossem planejadas e espacialmente visualizadas a partir de simulações 4D e da linha de balanço.

O método proposto, diferentemente dos trabalhos de Schramm (2009), Biotto (2012) e Reck (2013), parte de uma Estrutura Hierárquica de Zonas de Trabalho para estruturar o planejamento. Esta estruturação permite uma análise anterior a definição de lotes de produção e transferência, mas ainda com foco na definição de uma EHZT que flexibilize a definição destes lotes. Logo, o método dá maior ênfase na alocação das porções de trabalho em zonas de trabalho bem definidas espacialmente, o que é facilitado pelo uso de BIM. Além disto, o método proposto, foca na integração entre os diferentes horizontes de planejamento, principalmente em se tratando das etapas de médio e curto prazo, sugerindo uma série de passos detalhados para alcançá-la.

Além disso, o método proposto sugere a necessidade de uma interface de integração entre o planejamento e orçamento, o que é resultado da associação de componentes de custos às tarefas, ambos alocados em zonas de trabalho bem definidas. Entretanto, devido a limitações de tempo e recursos, o presente trabalho não foi a fundo na gestão de custos integrada ao PCP baseado em zonas de trabalho, existindo a necessidade de futuros estudos sobre o tema.

Do ponto de vista teórico, a abordagem proposta permitiu lidar com a natureza de empreendimentos de construção que são parcialmente repetitivos, por meio da estruturação das zonas de trabalho. Além disso, o método permitiu aplicar explicitamente alguns conceitos e princípios da produção enxuta, tais como a definição de lotes pequenos de produção, o planejamento e controle dos fluxos do produto e do trabalho, o controle do trabalho em progresso, a partir da alocação das atividades ao longo das zonas de trabalho. As simulações 4D forneceram informações visuais a respeito destes fluxos, contribuindo para apoiar a tomada de decisão referente ao planejamento. Os modelos BIM foram também utilizados para apoiar a realização de reuniões de planejamento e de médio e curto prazo do LPS, contribuindo com informações visuais a respeito 
das tarefas e da configuração espacial do projeto, as quais facilitam as reuniões de planejamento colaborativo e a gestão de compromissos.

A implementação deste método ocorreu de forma parcial em duas empresas do mercado imobiliário, permitindo obter informações consistentes e relevantes para analisar, discutir e comunicar os planos. Destacase a consideração nas reuniões de PCP de alguns conceitos e princípios da filosofia da produção enxuta, destacando-se a redução do tamanho dos lotes de produção, cuja visualização ocorreu diretamente no modelo BIM. Além deste, houve uma ênfase na transparência de processos, como consequência das informações gráficas geradas, tais como os snapshots do modelo 4D, a linha de balanço e o quadro de controle, os quais permitiram que os envolvidos entendessem melhor o escopo do planejamento. O método ainda trouxe um aumento da colaboração, gerado pela necessidade de maior envolvimento das equipes de planejamento e custos, o que foi observado nas reuniões realizadas com ambas as equipes para discutir o nível de desenvolvimento do modelo 3D. Isto contribuiu para criar melhoria contínua, pois o monitoramento forneceu informações em curtos ciclos de controle, que permitiram apoiar a tomada de decisão no PCP.

Na etapa de definição do plano de longo prazo e nas reuniões de médio e curto prazo realizadas ao longo dos estudos empíricos constatou-se que a utilização da linha de balanço em conjunto com o modelo 4D e o quadro de controle visual formam uma solução eficaz para visualizar os aspectos relacionados ao fluxo de trabalho, informações a respeito do produto, do escopo do plano e da configuração espacial do projeto. Destacou-se o potencial do modelo 4D para visualizar onde o trabalho estava alocado, o tamanho dos lotes de produção e de transferência, e o sequenciamento das atividades. O quadro de controle permitiu também visualizar o status das atividades monitoradas por meio de cores, trazendo evidências das datas de início e término planejadas e reais em cada zona de trabalho.

Outra contribuição refere-se à necessidade de identificar as necessidades específicas dos usuários do modelo BIM (equipes de planejamento e custos), que, ao serem consideradas, aumentaram a flexibilidade de saída e permitiram que fossem realizadas simulações $4 \mathrm{D}$ de forma a verificar melhores alternativas ao planejamento.

Como sugestões de trabalhos futuros podem-se apontar:

(a) ampliar o escopo do método proposto para contextos no qual existe menos repetitividade, já que tende a haver nos mesmos mais dificuldades para definir a EHZT;

(b) investigar a fundo as mudanças necessárias pela integração entre modelagem 4D e 5D, visando a integrar os processos de orçamentação, PCP, e controle de qualidade; e

(c) explorar novas formas de modelagem 5D, considerando as decisões tomadas na produção, ao invés de simplesmente reproduzir modelos tradicionais de estimativas de custo, que não consideram explicitamente atividades que não agregam valor.

\section{Referências}

BALLARD, G.; HOWELL, G. Implementing lean construction: improving downstream performance. In: ALARCÓN, L. (Ed.). Lean construction, p. 111-125, 1997.

BALLARD, G.; HOWELL, G. Shielding production: essential step in production control. Journal of Civil Engineering and Management, v. 124, n. 1, p. 11-17, 1998.

BALLARD, H. G. The Last Planner System of production control. Birmingham, 2000. Thesis (Ph.D) School of Civil Engineering, Faculty of Engineering, University of Birmingham, Birmingham, 2000.

BATAGLIN, F. S. et al. BIM 4D aplicado à gestão logística: implementação na montagem de sistemas préfabricados de concreto engineer-to-order. Ambiente Construído, Porto Alegre, v. 18, n. 1, p. 173-192, jan./mar. 2018.

BENJAORAN, V.; TABYANG, W.; SOOKSIL, N. Precedence relationship options for the resource levelling problem using a genetic algorithm. Construction Management and Economics, v. 33, n. 9, p. 711-723, 2015.

BIOTTO, C. N. Método para projeto e planejamento de sistemas de produção na construção civil com uso de modelagem BIM 4D. Porto Alegre, 2012. Dissertação (Mestrado em Engenharia Civil) - Programa de Pós-graduação em Engenharia Civil, Universidade Federal do Rio Grande do Sul, Porto Alegre, 2012. 
BIOTTO, C. N.; FORMOSO, C. T.; ISATTO, E. L. Uso de modelagem 4D e Building Information Modeling na gestão de sistemas de produção em empreendimentos de construção. Ambiente Construído, Porto Alegre,v. 15, n. 2, p. 65-77, abr./jun. 2015.

BIOTTO, C. et al. Comparing production design activities and location-based planning tools. In: ANNUAL CONFERENCE INTERNATIONAL GROUP FOR LEAN CONSTRUCTION, 25., Heraklion, 2017. Proceedings [...] Heraklion, 2017.

BJÖRNFOT, A.; JONGELING, R. Application of line-of-balance and 4D CAD for Lean Planning. Construction Innovation, v. 7, n. 2, p. 200-211, 2007.

BOTON, C.; KUBICKI, S.; HALIN, G. The challenge of level of development in 4D/BIM simulation across AEC Project lifecyle: a case study. Procedia Engineering, v. 123, p. 59-67, 2015.

BØLVIKEN, T.; ASLESEN, S.; KOSKELA, L. What is a good plan?. In: ANNUAL CONFERENCE INTERNATIONAL GROUP FOR LEAN CONSTRUCTION, 23., Perth, 2015. Proceedings [...] Perth, 2015.

CROTTY, R. The impact of Building Information Modelling: transforming construction. Routledge, 2012.

DAVE, B. et al. Suggestions to improve Lean Construction Planning. In: ANNUAL CONFERENCE INTERNATIONAL GROUP FOR LEAN CONSTRUCTION, 23., Perth, 2015. Proceedings [...] Perth, 2015.

EASTMAN, C. et al. BIM handbook: a guide to Building Information Modeling for owners, managers, designers, engineers and contractors. $2^{\text {nd }}$ ed. Wiley, 2011.

EDEN, C.; HUXHAM, C. Action research for management research. British Journal of Management, v. 7, n. 1, p. 75-86, 1996.

FORMOSO, C. A knowledge based framework for planning house building projects. Salford: University of Salford - Department of Quantity and Building Surveying, 1991.

FRANDSON, A. G.; SEPPÄNEN, O.; TOMMELEIN, I.D. Comparison between location based management and takt time planning. In: ANNUAL CONFERENCE INTERNATIONAL GROUP FOR LEAN CONSTRUCTION, 23., Perth, 2015. Proceedings [...] Perth, 2015.

HAMZEH, F.; BALLARD, G.; TOMMELEIN, I. D. Rethinking look ahead planning to optimize construction workflow. Lean Construction Journal, v. 1, n. 1, p. 15-34, 2012.

HAMZEH, F.; ZANKOUL, E.; ROUHANA, C. How can 'tasks made ready’ during lookahead planning impact reliable workflow and project duration? Construction Management and Economics, v. 33, n. 4, p. 243-258, 2015.

HARRIS, R. B.; IOANNOU, P. G. Scheduling projects with repeating activities. Journal of Construction Engineering and Management, v. 124, n. 4, p. 269-278, 1998.

HEGAZY, T.; KAMARAH, E. Efficient repetitive scheduling for high-rise construction. Journal of Construction Engineering and Management, v. 134, n. 4, p. 253-264, 2008.

HOLMSTRÖM, J.; KETOKIVI, M.; HAMERI, A.-P. Bridging practice and theory: a design science approach. Decision Science, v. 40, n. 1, p. 65-87, 2009.

HOPP, W. J.; SPEARMAN, M. L. Factory physics. New York: McGraw-Hill/Irwin, 2000.

HUANG, R.Y.; SUN, K. S. System development for non-unit based repetitive project scheduling. Automation in Construction, v. 14, n. 5, p. 650-665, 2005.

JÄRVINEN, P. Action research is similar to design science. Quality \& Quantity, v. 41, n. 1, p. 37-54, 2007.

JONGELING, R.; OLOFSSON, T. A Method for planning of work-flow by combined use of location-based scheduling and 4D CAD. Automation in Construction, v. 16, n. 2, p. 189-198, 2007.

KENLEY, R.; SEPPÄNEN, O. Location-based management for construction: planning, scheduling and control. London: Spon Press, 2010.

KOSKELA, L. An exploration towards a production theory and its application to construction. Espoo, 2000. Thesis (Ph.D) - Technical Research Center of Finland, Espoo, 2000. 
KOSKELA, L.; HOWELL, G. The underlying theory of project management is obsolete In: PROJECT MANAGEMENT INSTITUTE RESEARCH CONFERENCE, Seattle, 2002. Proceedings [...] Seattle, 2002.

KOSKELA, L. et al. If CPM is so bad, why have we been using it so long? In: ANNUAL CONFERENCE INTERNATIONAL GROUP FOR LEAN CONSTRUCTION, 22., Oslo, 2014. Proceedings [...] Oslo, 2014.

LAUFER, A. Essentials of project planning: owner's perspective. Journal of Management in Engineering, New York, ASCE, v. 6, n. 2, p. 162-176, 1990.

LAUFER, A. Simultaneous management: managing projects in a dynamic environment. AMACOM New York. 1997.

LAUFER, A.; TUCKER, R. L. Is Construction project planning really doing its job? A critical examination of focus, role and process. Construction Management and Economics, v. 5, n. 3, p. 243-266, 1987.

LUCKO, G.; ALVES, T. C. L.; ANGELIM, V. L. Challenges and opportunities for productivity improvement studies in linear, repetitive, and location-based scheduling. Construction Management and Economics, v. 32, n. 6, p. 575-594, 2014.

MATTILA, K. G.; PARK, A. Comparison of linear scheduling model and repetitive scheduling method. Journal of Construction Engineering and Management, v. 129, n. 1, p. 56-64, 2003.

OLIVIERI, H.; GRANJA, A. D.; PICCHI, F. A. Planejamento tradicional, Location-Based Management System e Last Planner System: um modelo integrado. Ambiente Construído, Porto Alegre, v. 16, n. 1, p. 265-283, jan./mar. 2016.

RECK, R. H. Proposta de Método para Integração da Simulação de Eventos Discretos e Visualização BIM 4D no Projeto do Sistema de Produção. Porto Alegre, 2013. Dissertação (Mestrado em Engenharia Civil) - Programa de Pós-Graduação em Engenharia, Universidade Federal do Rio Grande do Sul, Porto Alegre, 2013.

REDA, R. M. RPM: Repetitive project modeling. Journal of Construction Engineering and Management, ASCE, v. 116, n. 2, p. 316-30, 1990.

RUSSEL, A.; WONG, W. New Generation of planning structures. Journal of Construction Engineering and Management, ASCE, v. 119, n. 2, p. 196-214, 1993.

SACKS, R. et al. Interaction of lean and Building Information Modeling in construction. Journal of Construction Engineering and Management, v. 136, n. 9, p. 968-980, 2010.

SACKS, R. What constitutes good production flow in construction? Construction Management and Economics, v. 34, n. 9, p. 641-656, 2016.

SCHRAMM, F. K. Projeto de sistemas de produção na construção civil utilizando simulação computacional como ferramenta de apoio à tomada de decisão. Tese (Doutorado em Engenharia Civil) Escola de Engenharia, Universidade Federal do Rio Grande do Sul, Porto Alegre, 2009.

SCHRAMM, F. K.; FORMOSO, C. T. Projeto de sistemas de produção na construção civil empregando simulação no apoio à tomada de decisão. Ambiente Construído, Porto Alegre, v. 15, n. 4, p. 165-182, out./dez. 2015.

SEPPÄNEN, O. A Comparison of takt time and LBMS planning Methods. In: ANNUAL CONFERENCE INTERNATIONAL GROUP FOR LEAN CONSTRUCTION, 22., Oslo, 2014. Proceedings [...] Oslo, 2014.

SEPPÄNEN, O.; BALLARD, G.; PESONEN, S. The combination of last planner system and location-based management system. Lean Construction Journal, p. 43-54, 2010.

TOMMELEIN, I. D.; BALLARD, G. Look-ahead planning: screening and pulling. In: SEMINÁRIO INTERNACIONAL A CONSTRUÇÃO SEM PERDAS, 2., São Paulo, 1997. Anais [...] São Paulo, 1997.

VALENTE, C. P. et al. Guidelines for developing a line of balance for non-repetitive areas (common areas) at a vertical residential building. In: ANNUAL CONFERENCE INTERNATIONAL GROUP FOR LEAN CONSTRUCTION, 22., Oslo, 2014. Proceedings [...] Oslo, 2014. 
VIANA, D. D. Integrated production planning and control model for engineer-to-order prefabricated building systems. Porto Alegre, 2015. Tese (Doutorado em Engenharia Civil) - Programa de Pós-graduação em Engenharia Civil, Universidade Federal do Rio Grande do Sul, Porto Alegre, 2015.

VICO OFFICE. Vico office LBS manager. Disponível em:

http://support.vicosoftware.com/FlareFiles/Content/Online\%20Help/Define\%20Location\%20Systems.htm. Acesso em: 14 dez. 2016.

WOMACK, J. P.; JONES D. T. A mentalidade enxuta nas empresas: elimine o desperdício e crie riqueza. 5. Ed. Rio de Janeiro: Campus, 1996.

YASSINE, T. et al. Implementing takt-time planning in construction to improve work flow. In: ANNUAL CONFERENCE INTERNATIONAL GROUP FOR LEAN CONSTRUCTION, 22., Oslo, 2014.

Proceedings [...] Oslo, 2014.

Fabricio Berger de Vargas

Programa de Pós-Graduação em Engenharia Civil: Construção e Infraestrutura | Universidade Federal do Rio Grande do Sul | Av. Osvaldo Aranha, 99, 70 andar | Porto Alegre - RS - Brasil | CEP 90035-190 | Tel.: (51) 3308-4848 | E-mail: engfabriciovargas@gmail.com

\section{Carlos Torres Formoso}

Programa de Pós-Graduação em Engenharia Civil: Construção e Infraestrutura | Universidade Federal do Rio Grande do Sul | E-Mail: formoso@ufrgs.br

\section{Ambiente Construído}

Revista da Associação Nacional de Tecnologia do Ambiente Construído Av. Osvaldo Aranha, 99 - 3o andar, Centro

Porto Alegre - RS - Brasil

$$
\text { CEP } 90035-190
$$

Telefone: +55 (51) 3308-4084

Fax: +55 (51) 3308-4054

www. seer. ufrgs. br/ ambienteconstruido

E-mail: ambienteconstruido@ufrgs.br

(c) () 